\title{
Sox17-dependent gene expression and early heart and gut development in Sox17-deficient mouse embryos
}

\author{
SABINE PFISTER ${ }^{1}$, VANESSA J. JONES ${ }^{1}$, MELINDA POWER ${ }^{1}$, GERMAINE L. TRUISI ${ }^{1}$, \\ POH-LYNN KHOO ${ }^{1}$, KIRSTEN A. STEINER ${ }^{1}$, MASAMI KANAI-AZUMA ${ }^{2}$, YOSHIAKIRA KANAI ${ }^{3}$, \\ PATRICK P. L. TAM ${ }^{1,4}$ and DAVID A. F. LOEBEL ${ }^{*, 1,4,5}$ \\ ${ }^{1}$ Embryology Unit, Children's Medical Research Institute, New South Wales, Australia, \\ ${ }^{2}$ Center for Experimental Animals, Tokyo Medical and Dental University, Tokyo, Japan, \\ ${ }^{3}$ Department of Veterinary Medicine, University of Tokyo, Tokyo, Japan and \\ ${ }^{4}$ Sydney Medical School, University of Sydney, New South Wales, Australia
}

\begin{abstract}
Sox17 is a transcription factor that is required for maintenance of the definitive endoderm in mouse embryos. By expression profiling of wild-type and mutant embryos and Sox17-overexpressing hepatoma cells, we identified genes with Sox17-dependent expression. Among the genes that were up-regulated in Sox17-null embryos and down-regulated by Sox17expressing HepG2 cells is a set of genes that are expressed in the developing liver, suggesting that one function of Sox17 is the repression of liver gene expression, which is compatible with a role for Sox17 in maintaining the definitive endoderm in a progenitor state. Consistent with these findings, Sox $17^{-1}$ cells display a diminished capacity to contribute to the definitive endoderm when transplanted into wild-type hosts. Analysis of gene ontology further revealed that many genes related to heart development were downregulated in Sox17-null embryos. This is associated with the defective development of the heart in the mutant embryos, which is accompanied by localised loss of Myocd-expressing cardiogenic progenitors and the malformation of the anterior intestinal portal.
\end{abstract}

KEY WORDS: Sox17, downstream gene, endoderm, heart morphogenesis

\section{Introduction}

Endoderm specification and differentiation during embryogenesis in frogs and fish involves transcriptional activation of zinc finger GATA factors, Mix-homeodomain proteins and High Mobility Group SOX proteins by TGF $\beta /$ Nodal signalling and T-box and POU-domain transcription factors (Kiefer, 2003; Lunde et al., 2004; Reim et al., 2004; Shivdasani, 2002; Stainier, 2002; Woodland and Zorn, 2008; Zorn and Wells, 2007; Zorn and Wells, 2009). A similar set of genes including Mix/Mixer, Sox17and Foxa is associated with endoderm formation in mouse, frogs and fish, but their function and regulation differ in mouse development.

The mouse Mix/1 gene is expressed in the primitive streak where the endoderm progenitors reside but not in the definitive endoderm (Pearce and Evans, 1999), unlike in Xenopus where Mix/Mixer expression is endoderm-specific. Mix/1 function is critical for the generation of definitive endoderm in the mouse.
Mix/1-null embryos contain a reduced population of endoderm that lacks the expression of molecular markers of definitive endoderm (Hart et al., 2002) and Mix/1-null embryonic stem cells and primitive streak cells are less efficient in populating the definitive endoderm (Hart et al., 2002; Tam et al., 2007). Whereas Sox17 is essential for endoderm formation in Xenopus and Zebrafish embryos, loss of Sox17in the mouse does not appear to affect lineage allocation but impairs the viability of the endoderm of the foregut and the proliferation of endoderm in the posterior gut (Kanai-Azuma et al., 2002; Tam et al., 2003). In Xenopus, the endodermal genes HNF1 1 , Foxa1, Foxa2 and Endoderminare direct transcriptional targets of Sox17 (Clements et al., 2003; Sinner et al., 2004). The expression of Foxa1 and

Abbreviations used in this paper: APS, anterior primitive streak; GO, gene ontology.

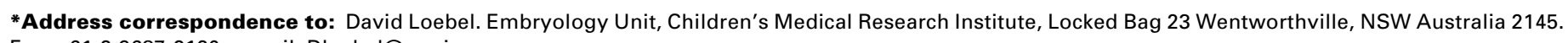
Fax: +61-2-9687-2120. e-mail: Dloebel@cmri.org.au

Supplementary Material (7 tables) for this paper is available at: http://dx.doi.org/10.1387/ijdb.103158sp 
Foxa2 is severely reduced in Sox17/- mouse embryos (Kanai-Azuma etal., 2002), but it is not clear whether they are direct transcriptional targets of Sox17.

At present, the transcriptional targets of Sox17in the mouse embryo at early-organogenesis when the nullmutant phenotype first manifests have not been identified. Previous studies dealing with Sox17-dependent gene expression in mammalian cells have used mouse or human embryonic stem (ES) cells, in which Sox17was over-expressed. Results conflicted between the two stem cell types, with Sox17inducing molecular characteristics of definitive endoderm in human ES cells (Seguin et al., 2008) but those of extraembryonic endoderm in mouse ES cells (Niakan et al., 2010). However, in mouse ES cells, Sox17 can induce both definitive and visceral endoderm differentiation under some circumstances ( $Q u$ et al., 2008). The variation in results between in vitro models suggests that Sox17-dependent changes in the transcriptome and the identification of potential Sox 17 transcriptional targets is influenced by the inherent properties of the cell model used.

In this study, we examined gene expression profiles in the mouse embryo, in which Sox17has been shown to be required for development of the definitive but not visceral endoderm, to identify Sox17-dependent changes in gene transcription. To

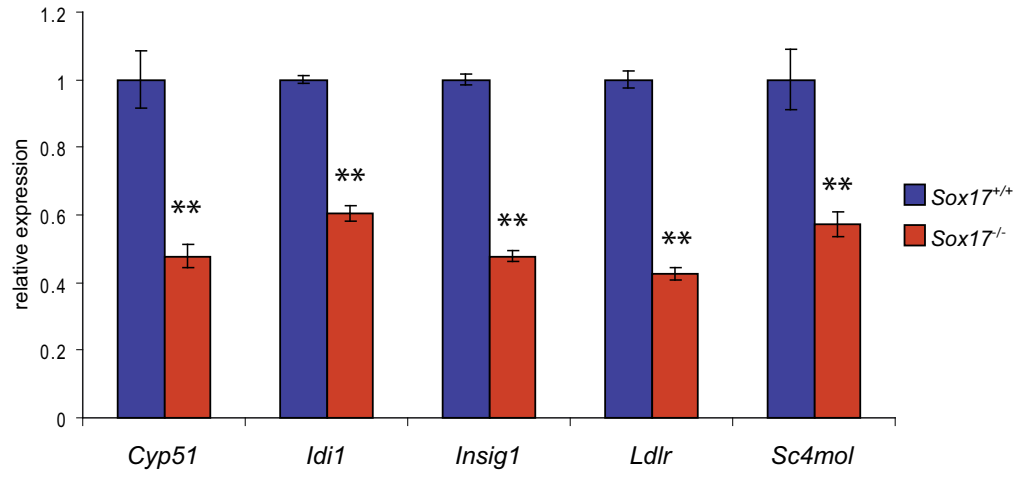

Fig. 1. Validation of the down-regulation of genes associated with cholesterol metabolism in Sox17/- embryos. Real-time quantitative RTPCR analysis was performed on cDNA generated from RNA samples of E8.25 Sox $17^{+/+}$and Sox $17-$ embryos. Expression levels are shown relative to wild-type. Gapd was the reference gene. Errorbars indicate standard error of the mean. $N=3$ for each assay. * * Significant difference at $p<0.01$ by two-tailed t-test from Sox $17^{+/+}$embryos.

identify possible Sox17 target genes, we compared the changes in gene expression profiles of mutant embryos with those resulting from Sox17-overexpression in HepG2 cells. The findings show that changes in Sox17activity impact on the genetic activity associated with endoderm development. Embryological analysis

TABLE 1

TOP 50 GENES SIGNIFICANTLY UP-REGULATED IN SOX17-/- EMBRYOS ORDERED BY LOG ${ }_{2}$ FOLD-CHANGE IN EXPRESSION

\begin{tabular}{|c|c|c|c|c|c|}
\hline Symbol & Description & GenBank & GO Biological functions summary & Probe & $\begin{array}{l}\log _{2} \\
\text { FoldChange }\end{array}$ \\
\hline Tsix & $\mathrm{X}$ (inactive)-specific transcript, antisense & BG806300 & dosage compensation; & 1436936_s_at & 3.27 \\
\hline Afp & alpha fetoprotein & NM_007423 & & $\begin{array}{l}\text { 1416645_a_at } \\
\text { 1416646_at } \\
1436879 \text { __at }\end{array}$ & $\begin{array}{l}3.14 \\
2.96 \\
2.63\end{array}$ \\
\hline Slc2a2 & $\begin{array}{l}\text { solute carrier family } 2 \text { (facilitated glucose transporter), } \\
\text { member } 2\end{array}$ & NM_031197 & carbohydrate transport & 1449067_at & 2.83 \\
\hline Tspan8 & tetraspanin 8 & BC025461 & & 1424649_a_at & 2.77 \\
\hline D7Ertd715e & DNA segment, Chr 7, ERATO Doi 715, expressed & BB314814 & & 1436964_at & 2.72 \\
\hline Timd2 & T-cell immunoglobulin and mucin domain containing 2 & BC028829 & & 1418766_s_at & 2.37 \\
\hline Apoc2 & apolipoprotein C-II & NM_009695 & lipid transport & 1418069_at & 2.35 \\
\hline$X I r 4 b$ & X-linked lymphocyte-regulated 4B & NM_021365 & & 1449347_a_at & 2.35 \\
\hline Apoa1 & apolipoprotein A-I & NM_009692 & endothelial cell proliferation; lipid transport & $\begin{array}{l}\text { 1438840_x_at } \\
1419232 \text { a_at } \\
1455201 \text { _x_at } \\
1419233 \text { _x_at }\end{array}$ & $\begin{array}{l}2.6 \\
2.55 \\
2.34 \\
2.28\end{array}$ \\
\hline Ccnb1ip1 & cyclin B1 interacting protein 1 & BG066504 & blastocyst formation; apoptosis & 1435998_at & 2.19 \\
\hline Fgg & fibrinogen, gamma polypeptide & NM_133862 & platelet activation & 1416025_at & 1.99 \\
\hline Lgals2 & lectin, galactose-binding, soluble 2 & NM_025622 & & 1417079_s_at & 1.89 \\
\hline Pdzk1 & PDZ domain containing 1 & AK006269 & & 1431701_a_at & 1.85 \\
\hline Cldn2 & claudin 2 & NM_016675 & calcium-independent cell-cell adhesion & 1417231_at & 1.82 \\
\hline Cubn & cubilin (intrinsic factor-cobalamin receptor) & AF197159 & receptor-mediated endocytosis & $\begin{array}{l}\text { 1426990_at } \\
1452270 \_s \_a t\end{array}$ & $\begin{array}{l}1.94 \\
1.8\end{array}$ \\
\hline$R b p 4$ & retinol binding protein 4 , plasma & U63146 & $\begin{array}{l}\text { eye development; spermatogenesis; lung development; } \\
\text { cardiac muscle development female genitalia } \\
\text { morphogenesis }\end{array}$ & 1426225_at & 1.8 \\
\hline 2410003J06Rik & RIKEN cDNA 2410003J06 gene & AK010362 & & 1429701_at & 1.75 \\
\hline Sfmbt2 & Scm-like with four mbt domains 2 & BM200222 & regulation of transcription & 1434353_at & 1.72 \\
\hline Trap1a & tumor rejection antigen $\mathrm{P} 1 \mathrm{~A}$ & NM_011635 & & 1460226_at & 1.7 \\
\hline Apoa4 & apolipoprotein A-IV & BC010769 & lipid transport; regulation of cholesterol absorption & 1417761_at & 1.68 \\
\hline Nrk & Nik related kinase & AK012873 & protein amino acid phosphorylation & $\begin{array}{l}\text { 1450078_at } \\
\text { 1450079_at }\end{array}$ & $\begin{array}{l}1.94 \\
1.65\end{array}$ \\
\hline Ttr & transthyretin & BG141874 & thyroid hormone generation & $\begin{array}{l}\text { 1455913_x_at } \\
1459737 \text { __at } \\
1451580 \text { a_at } \\
1454608 \text { x_at }\end{array}$ & $\begin{array}{l}1.77 \\
1.71 \\
1.65 \\
1.64\end{array}$ \\
\hline
\end{tabular}




\begin{tabular}{|c|c|}
\hline$A m n$ & amnionless \\
\hline$F g b$ & fibrinogen, $B$ beta polypeptide \\
\hline Spp2 & secreted phosphoprotein 2 \\
\hline XIr3a & X-linked lymphocyte-regulated $3 \mathrm{~A}$ \\
\hline Paip1 & polyadenylate binding protein-interacting protein 1 \\
\hline Vil1 & villin 1 \\
\hline Мғар3l & microfibrillar-associated protein 3-like \\
\hline Rab11fip5 & RAB11 family interacting protein 5 (class I) \\
\hline Ctsh & cathepsin $\mathrm{H}$ \\
\hline 2610528J11Rik & RIKEN cDNA 2610528J11 gene \\
\hline Mbl2 & mannose-binding lectin (protein C) 2 \\
\hline $\mathrm{Npl}$ & $\mathrm{N}$-acetylneuraminate pyruvate lyase \\
\hline Slc7a9 & $\begin{array}{l}\text { solute carrier family } 7 \text { (cationic amino acid transporter, y- } \\
\text { system), member } 9\end{array}$ \\
\hline$T d h$ & L-threonine dehydrogenase \\
\hline Car7 & carbonic anhydrase 7 \\
\hline Soat2 & sterol O-acyltransferase 2 \\
\hline Trf & transferrin \\
\hline Fga & fibrinogen, alpha polypeptide \\
\hline Rhox5 & reproductive homeobox 5 \\
\hline Slco4c1 & $\begin{array}{l}\text { solute carrier organic anion transporter family, member } \\
4 C 1\end{array}$ \\
\hline Reep6 & receptor accessory protein 6 \\
\hline Aass & aminoadipate-semialdehyde synthase \\
\hline Morc4 & microrchidia 4 \\
\hline Lgmn & legumain \\
\hline Adora2b & adenosine $\mathrm{A} 2 \mathrm{~b}$ receptor \\
\hline Cfi & complement component factor i \\
\hline Gpr155 & G protein-coupled receptor 155 \\
\hline Dab2 & disabled homolog 2 (Drosophila) \\
\hline
\end{tabular}

\begin{tabular}{|c|c|c|c|}
\hline NM_033603 & excretion & 1417920_at & 1.6 \\
\hline AK011118 & platelet activation & 1428079_at & 1.53 \\
\hline NM_029269 & bone remodeling & 1418916_a_at & 1.53 \\
\hline NM_011726 & & 1420357_s_at & 1.5 \\
\hline BB381990 & regulation of translation & $\begin{array}{l}\text { 1425521_att } \\
\text { 1441955_s_a }\end{array}$ & $\begin{array}{l}1.49 \\
1.61\end{array}$ \\
\hline NM_009509 & cytoskeleton organization & 1448837_at & 1.41 \\
\hline AV262974 & & $\begin{array}{l}\text { 1428804_at } \\
\text { 1441481_at }\end{array}$ & $\begin{array}{l}1.46 \\
0.92\end{array}$ \\
\hline BF682225 & protein transport & $\begin{array}{l}\text { 1434314_s_at } \\
\text { 1427405_s_at }\end{array}$ & $\begin{array}{c}1.4 \\
0.62\end{array}$ \\
\hline NM_007801 & proteolysis & $\begin{array}{l}\text { 1443814_x_at } \\
1418365 \_ \text {at }\end{array}$ & $\begin{array}{l}1.39 \\
1.46\end{array}$ \\
\hline AK012175 & & 1450947_at & 1.39 \\
\hline NM_010776 & innate immune response & 1418787_at & 1.38 \\
\hline BC022734 & carbohydrate metabolic process & 1424265_at & 1.37 \\
\hline NM_021291 & amino acid transport & 1448783_at & 1.36 \\
\hline NM_021480 & cellular metabolic process & 1449064_at & 1.36 \\
\hline BB193643 & & 1443824_s_at & 1.35 \\
\hline BC025931 & lipid; steroid; cholesterol metabolic process & 1460722_at & 1.35 \\
\hline AF440692 & iron ion transport & 1425546_a_at & 1.33 \\
\hline BC005467 & blood coagulation & 1424279_at & 1.31 \\
\hline BM210473 & sperm motility; germ cell programmed cell death & 1423429_at & 1.3 \\
\hline AV024403 & spermatogenesis; organic anion transport c & $\begin{array}{l}\text { 1437870_at } \\
\text { 1460616_at }\end{array}$ & $\begin{array}{l}1.27 \\
1.29\end{array}$ \\
\hline AK002562 & & 1430128_a_at & 1.24 \\
\hline BF687395 & generation of precursor metabolites & 1423523_at & 1.22 \\
\hline AV036158 & & 1434436_at & 1.18 \\
\hline NM_011175 & negative regulation of growth & 1448883_at & 1.16 \\
\hline BB709140 & $\begin{array}{l}\text { mast cell degranulation; relaxation of vascular smooth } \\
\text { muscle }\end{array}$ & $\begin{array}{l}\text { 1434430_s_att } \\
\text { 1434431_x_a }\end{array}$ & $\begin{array}{l}1.16 \\
0.78\end{array}$ \\
\hline NM_007686 & $\begin{array}{l}\text { proteolysis immune response complement activation; } \\
\text { classical pathway }\end{array}$ & 1418724_at & 1.15 \\
\hline BB762731 & & 1452353_at & 1.14 \\
\hline NM_023118 & cell morphogenesis & 1420498_a_at & 1.14 \\
\hline
\end{tabular}

further shows that Sox17-null cells are less efficient in contributing to the definitive endoderm. Loss of Sox17 in the endoderm also disrupts form-shaping activity in the anterior intestinal portal and the morphogenesis of the heart tube. Sox17-null mutant embryos also showed defective differentiation of the cardiogenic mesoderm. These findings are consistent with the definitive endoderm being a source of morphogenetic cues that patterns the tissues associated with the gut (Lewis and Tam, 2006),

\section{Results}

\section{Identification of Sox17-dependent changes in gene expres- sion}

To identify Sox17-dependent gene expression we compared the expression profile of Sox17-null mutant and wild type embryos at the 4-5 somite stage, in order to capture the changes in the transcriptome before the Sox17-null phenotype becomes morphologically evident (Kanai-Azuma et al., 2002). This was expected to minimize the confounding effects caused by secondary changes in gene expression due to aberrant development. Among the up-regulated transcripts in the mutant embryos, there is a preponderance of those encoding apolipoproteins and solute transporters (Table 1, Supplementary Table S1). This is reflected in the over-representation of genes defined by Gene Ontology (GO) biological function terms relating to homeostasis, absorption, transport as well as cholesterol, steroid and lipid metabolism, catabolism and biosynthesis (Table 2A). These genes include Apoa1, Apob, Apoc2, Apom and S/c2a2 that are known to be expressed primarily in the extraembryonic visceral endoderm during post-implantation development. Other genes that are expressed in the visceral endoderm were also upregulated in mutant embryos (including Afp, Cubn, Dab, Rbp4, Rhox5 and Ttr; Table 1, Supplementary Table S1). Some of these putative visceral endoderm genes (e.g.: Afp, Ttrand Apofamily members) are also expressed in the liver later in development but they are normally only expressed at low levels in the foregut endoderm of wild-type early-somite stage embryos. The profiling results are consistent with the observation that definitive endoderm is replaced by cells displaying phenotypes characteristic of the extraembryonic visceral endoderm in the embryonic gut region of the Sox17-null mutant (Kanai-Azuma et al., 2002). Alternatively, it may be that one function of Sox 17 is to maintain liver-specific gene expression at a low level in the early definitive endoderm.

Among the genes that were down-regulated in the mutant embryos (Table 3, Supplementary Table S1), there is an overrepresentation of genes involved in pathways for biosynthesis, metabolism and transport of lipids and cholesterol (Table 2B). Transcripts of genes involved in cholesterol biosynthesis (Cyp51, Idi1, Insig1 and Sc4mol) and transport ( $L d l i)$ showed reduced expression in the absence of Sox17, and downregulation was validated by qRT-PCR (Fig. 1). Cholesterol is a key component of the Hedgehog signalling pathway that is essential for patterning the primitive gut tube (Harmon et al., 2002). Notably, the concerted changes of the cholesterol pathway genes are consistent with the concept that cholesterogenic enzymes constitute a synexpression group in embryos and cultured fibroblasts (lyer et 
al., 1999; Laubner et al., 2003; Marijanovic et al., 2003). In the Sox17-null embryo, expression of Ihh in the gut endoderm and Ptch1in the lateral plate mesoderm is down-regulated, indicating that loss of Sox17 function is associated with reduced Hedgehog signalling activity (Kanai-Azuma et al., 2002). Also of note is the reduced expression of Nepn (Table 3, Supplementary Table S1), which is normally expressed in the lateral midgut endoderm at this stage (Hou et al., 2007). Its down-regulation is consistent with the depletion of definitive endoderm in the mutant embryos.

Analysis of networks of transcriptional targets using Metacore (www.genego.com) revealed that 75 of the differentially expressed genes were also potentially regulated by Hnf4, with either a known effect on transcription or evidence for binding of Hnf4 to

\section{A}

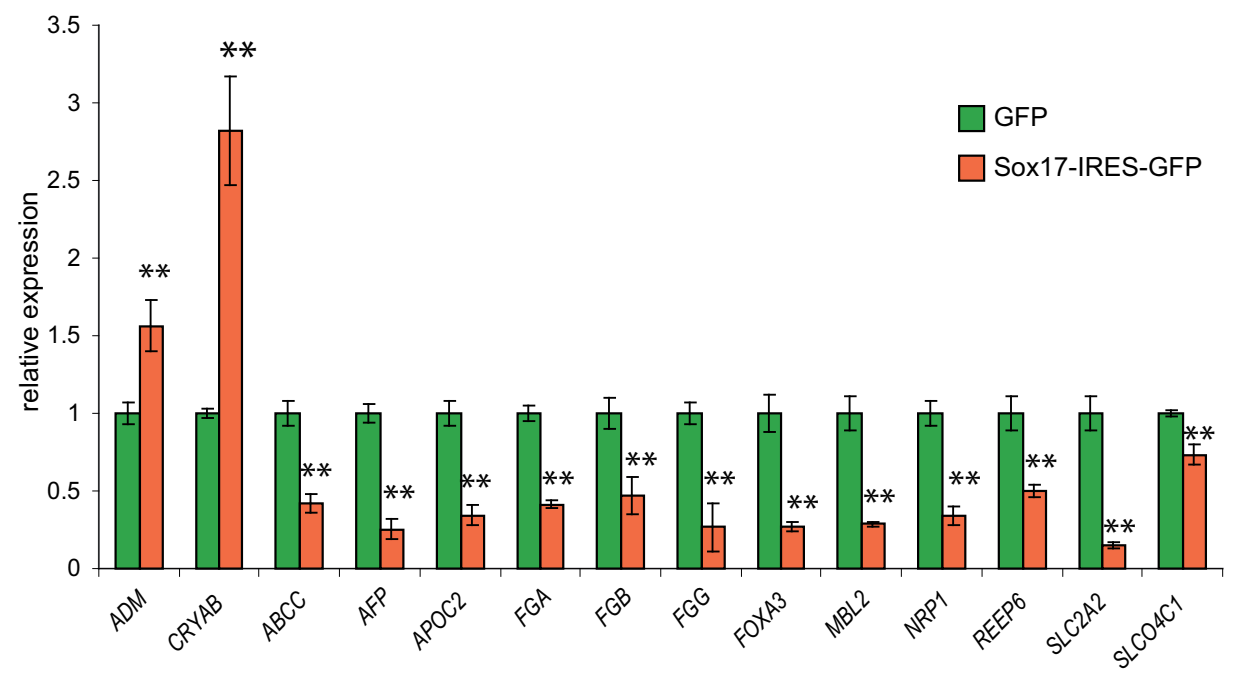

B

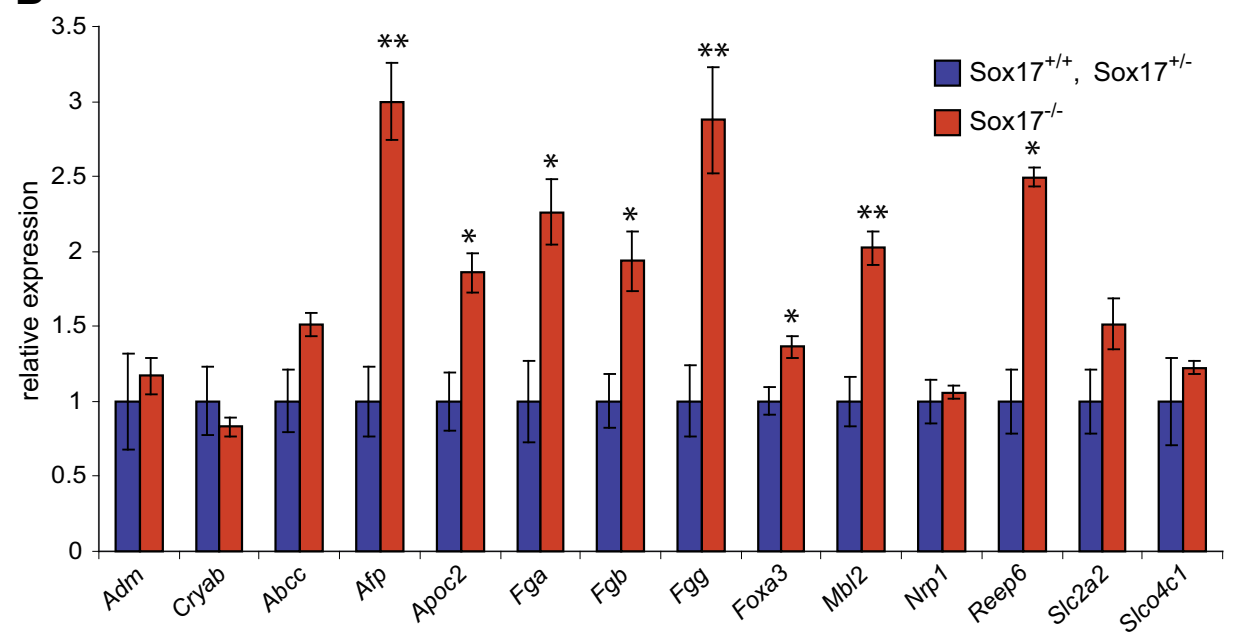

Fig. 2. Validation of the microarray results of differential gene expression in HepG2 cells overexpressing Sox17-IRES-GFP and in Sox 17\% embryos. Real-time quantitative RTPCR analysis was performed on cDNA generated from: (A) RNA samples of HepG2 cells transfected with GFP only or Sox17-IRES-GFP expression vector; and (B) RNA samples of 6-8 somite Sox $17^{+/+}$and Sox $17^{+1-}$ or Sox $17^{-1-}$ embryos. Expression levels are shown relative to GFP only (A) or Sox $17^{+1-}$ Sox $17^{+-}$embryos (B). POLR2A was the reference gene for $(A)$ and Gapd was the reference gene for $(B)$. Error bars indicate standard error of the mean. $N=4$ for Sox $17^{+/+}$, Sox $17^{+/}$and $N=3$ for each all others. ${ }^{*}$ Significant difference at $p<0.01$ or ${ }^{*}$ at $p<0.05$ by two-tailed t-test from GFP-only expressing cells or Sox $17^{+/+} /$Sox $17^{+/-}$embryos. putative regulatory regions (Supplementary Fig. S1). Hnf4 is expressed in liver and visceral endoderm suggesting a change in composition of the gut or dys-regulation of genes associated with liver development. Sox17may also be regulated by Hnf4via cross-acting Hnf4 and Sox17transcriptional networks. construct expressing Sox17 along with a GFP reporter. Transfected cells were sorted for GFP expression, and expression profiles analysed using Illumina human Sentrix-6 chips. Results were filtered for significantly different expression levels between GFP-only and Sox 17-IRES-GFP transfected cells (Supplementary Table S2). The list of differentially expressed genes was compared to the list of genes that were differentially expressed between wild-type and Sox17-mutant embryos, and we identified 32 genes that were differentially expressed in both sets of data (Table 4). Of these, 21 showed concordance between the two data sets; that is, these genes were up-regulated in the HepG2 over-expressing Sox17 but down-regulated in Sox17-null embryos, and vice versa. These 21 genes are therefore potential candidates for positive or negative regulation by $S 0 \times 17$. Results of qRT-PCR have validated in the majority of cases the differential expression of these genes in transfected HepG2 cells (Fig. 2A) and in embryos (Fig. 2B).

Two previous studies have addressed the question of Sox17-dependent gene expression either in mouse (Niakan etal., 2010) or human (Seguin et al., 2008) ES cells in which Sox17was over-expressed. To gain additional insights into the genes that potentially act downstream of Sox 17 we compared our embryo and HepG2 microarray data to these studies. Comparing the list of genes that were up- or down-regulated in Sox17-null embryos with those that were changed in the opposite direction in Sox17-over-expressing mouse (Niakan et al., 2010) and human (GEO accession GSE10809) ES cells revealed an overlap of 6 genes each in the embryo-mouse ES and embryohuman ES sets. These genes are involved in diverse processes including metabolism (folic acid, TCA, sorbitol, carbohydrate), cytoskeletal arrangement, transcription and cell proliferation (Supplementary Table S3A, B).There 
were no genes common to both sets. Most likely, this reflects the different effects of Sox17over-expression in the two cell models. In mouse ES cells, Sox17 appears to direct extraembryonic endoderm differentiation, whereas in human ES cells, Sox17 overexpression results in up-regulation of genes that are characteristic of definitive endoderm. Among the genes of the embryomouse ES and embryo-human ES sets, Adm, Fgb, Folr1 were also detected by ChIP from mouse ES or extraembryonic endoderm stem (XEN) cells (Niakan et al., 2010) suggesting that Sox17 may act directly on these genes.

Comparison of genes with changed expression levels in Sox17mutant embryos and Sox17-overexpressing human ES cells (Seguin et al., 2008) revealed a set of genes that encode proteins that affect diverse processes including actin cytoskeleton organization (CDC42, RDX), proliferation and differentiation (FST, GNG4, SERPINE2) and responses to signalling (ACSL4, ADM, FST, GNG4, STC2; Supplementary Table S4). The best candidates Sox17-regulated genes in the definitive endoderm are those that are differentially expressed in Sox17-null embryos and in the over-expression HepG2 cells and to which Sox17 binds. Comparison with published data (Niakan et al., 2010), (Supplementary Table S5) revealed a set of six genes that fulfilled this criterion amongst those identified by ChIP of ES cells only ( $F g b, S / C O 4 c 1)$, XEN cells only (Mbla) or both ES and XEN cells (Adm, Nrp1, $R b m 4 b)$.

\section{Sox17-deficient cells contribute less efficiently to gut endo- derm}

Our microarray studies revealed a higher representation of transcripts of genes that are characteristic of extraembryonic visceral endoderm in the Sox17-null embryo, suggesting a preponderance of this type of endoderm in the early-somite stage Sox17-null embryo. This is consistent with findings that Sox17/embryo is depleted of definitive endoderm, which is partly replaced by cells that display properties of extraembryonic visceral endoderm (Kanai-Azuma et al., 2002). To test directly whether Sox17-deficient progenitor cells are compromised in their ability to populate the gut endoderm, the fates of cells of the anterior segment of the primitive streak (APS) of gastrula-stage embryos, where the progenitors of definitive endoderm are localised (Kinder et al., 2000), were analysed by orthotopic transplantation to wild type recipient embryos (Fig. $3 \mathrm{~A}, \mathrm{H}$ ). Fluorescence imaging of the recipient embryos cultured for 29 hours revealed a widespread distribution of the EGFP and lacZ-expressing APS-derived cells from Sox $17^{t /+}$ and Sox $17^{t /}$ donor in the host embryos (Fig. $3 \mathrm{~B}$, B', E, E') and to tissues derived from different germ layers (Fig. 3 C, D, F, G). Although a similar average number of cells were generated by grafts of Sox17/-APS cells, a smaller proportion of graft-derived cells were found in the gut endoderm and the presomitic mesoderm (Fig. $3 \mathrm{I-N}$, Table 5). Instead, Sox $17^{/-}$cells were found more frequently in the ectoderm of the posterior neural tube and the extraembryonic mesoderm (Table 5). Sox17/- APS cells therefore are impaired in their ability to contribute to gut endoderm.

\section{Morphogenesis of the anterior intestinal portal is disrupted in Sox17-- embryos}

Cells of the anterior definitive endoderm cells are fated to become the endoderm of the anterior intestinal portal (the foregut invagination) that forms the upper digestive tract and associated organs (Tremblay and Zaret, 2005). In wild type and heterozygous mutant embryos, formation of the anterior intestinal portal proceeded first by invagination, followed by anterior extension and narrowing of the foregut pocket (Fig. $4 \mathrm{~A}, \mathrm{~B}, 0,5$ and $23 \mathrm{hrs}$ )

\section{TABLE 2}

\section{SIGNIFICANTLY OVER-REPRESENTED GENE ONTOLOGY BIOLOGICAL FUNCTION TERMS AMONGST GENES THAT WERE UP- OR DOWNREGULATED IN SOX17/- EMBRYOS}

\begin{tabular}{ccccl} 
(A) Upregulated in Sox $\mathbf{1 7}^{\text {/ }}$ embryos & & \\
\hline P value & Odds & Expected & & \\
\hline 0.000 & 69.201 & 0 & 3 & cellular zinc ion homeostasis \\
0.000 & 3.533 & 5 & 15 & response to wounding \\
0.000 & 51.896 & 0 & 3 & lipoprotein transport \\
0.000 & 6.084 & 1 & 7 & regulation of body fluid levels \\
0.000 & 5.866 & 1 & 7 & lipid transport \\
0.001 & 68.800 & 0 & 2 & regulation of cholesterol absorption \\
0.001 & 68.800 & 0 & 2 & cholesterol efflux \\
0.002 & 45.863 & 0 & 2 & negative regulation of blood coagulation \\
0.002 & 45.863 & 0 & 2 & lipid digestion \\
0.002 & 13.826 & 0 & 3 & regeneration \\
0.002 & 13.826 & 0 & 3 & vasodilation \\
0.003 & 34.394 & 0 & 2 & lipoprotein catabolic process \\
0.003 & 11.519 & 0 & 3 & cholesterol homeostasis \\
0.003 & 5.358 & 1 & 5 & cholesterol metabolic process \\
0.004 & 10.912 & 0 & 3 & blastocyst formation \\
0.004 & 10.912 & 0 & 3 & zinc ion transport \\
0.005 & 4.796 & 1 & 5 & negative regulation of multicellular organismal \\
& & & & process \\
0.005 & 23.371 & 0 & 2 & lipoprotein metabolic process \\
& & & & \\
0.006 & 9.011 & 0 & 3 & Gastrulation in deuterostomes \\
0.006 & 9.011 & 0 & 3 & iron ion transport \\
0.006 & 9.011 & 0 & 3 & lipid homeostasis \\
0.006 & 3.428 & 2 & 7 & steroid metabolic process \\
0.006 & 3.879 & 2 & 6 & di-, tri-valent inorganic cation homeostasis \\
0.007 & 3.808 & 2 & 6 & cellular cation homeostasis \\
0.007 & 2.235 & 7 & 14 & reproduction \\
0.007 & 19.649 & 0 & 2 & axon regeneration \\
0.007 & 5.660 & 1 & 4 & lipoprotein biosynthetic process \\
& & & &
\end{tabular}

(B) Downregulated in Sox $17^{/ /}$embryos

\begin{tabular}{ccccl}
\hline P value & $\begin{array}{c}\text { Odds } \\
\text { Ratio }\end{array}$ & $\begin{array}{c}\text { Expected } \\
\text { Count }\end{array}$ & Count & Term \\
\hline 0.000 & 38.762 & 0 & 6 & cholesterol biosynthetic process \\
0.000 & 6.713 & 2 & 14 & cellular alcohol metabolic process \\
0.000 & 12.039 & 1 & 7 & steroid biosynthetic process \\
0.000 & 3.184 & 5 & 15 & oxidation reduction \\
0.001 & 11.490 & 0 & 4 & cholesterol metabolic process \\
0.001 & 18.822 & 0 & 3 & cholesterol homeostasis \\
0.002 & 14.724 & 0 & 3 & lipid homeostasis \\
0.004 & 6.822 & 1 & 4 & steroid metabolic process \\
0.004 & 4.325 & 1 & 6 & lipid biosynthetic process \\
0.006 & 20.544 & 0 & 2 & isoprenoid biosynthetic process \\
0.009 & 3.580 & 2 & 6 & heart development \\
0.009 & Infinite & 0 & 1 & S-adenosylmethionine biosynthetic process \\
0.009 & Infinite & 0 & 1 & isoprenoid catabolic process \\
0.009 & Infinite & 0 & 1 & low-density lipoprotein receptor metabolic \\
& & & & process \\
0.009 & Infinite & 0 & 1 & regulation of low-density lipoprotein receptor \\
& & & & catabolic process \\
0.009 & Infinite & 0 & 1 & muscle cell fate specification \\
0.009 & Infinite & 0 & 1 & arachidonic acid secretion \\
\hline
\end{tabular}




\section{S. Pfister et al.}

TABLE 3

\section{TOP 50 GENES THAT WERE SIGNIFICANTLY DOWN-REGULATED IN SOX17/- EMBRYOS ORDERED BY LOG ${ }_{2}$ FOLD CHANGE IN EXPRESSION}

\begin{tabular}{|c|c|c|c|c|c|}
\hline Symbol & Description & GenBank & GO Biological functions summary & Probe & $\begin{array}{c}\log _{2} \\
\text { FoldChange }\end{array}$ \\
\hline Sox17 & SRY-box containing gene 17 & AK004781 & $\begin{array}{l}\text { angiogenesis; vasculogenesis; negative regulation of } \\
\text { Wnt receptor signaling pathway }\end{array}$ & $\begin{array}{l}\text { 1429177_x_at } \\
\text { 1421657_a_at }\end{array}$ & $\begin{array}{l}-4.88 \\
-1.24\end{array}$ \\
\hline Eif2s3y & $\begin{array}{l}\text { eukaryotic translation initiation factor } 2 \text {, subunit } 3 \text {, structural } \\
\text { gene Y-linked }\end{array}$ & NM_012011 & translation & 1417210_at & -3.7 \\
\hline$D d x 3 y$ & DEAD (Asp-Glu-Ala-Asp) box polypeptide 3, Y-linked & AA210261 & & 1426438_at & -3.65 \\
\hline Prl8a2 & prolactin family 8, subfamily a, member 2 & NM_010088 & response to hypoxia & 1448608_at & -2.72 \\
\hline Jarid1d & jumonji, AT rich interactive domain 1D (Rbp2 like) & AF127244 & chromatin modification & 1424903_at & -2.39 \\
\hline Uty & $\begin{array}{l}\text { ubiquitously transcribed tetratricopeptide repeat gene, } \mathrm{Y} \\
\text { chromosome }\end{array}$ & BB742957 & chromatin modification & $\begin{array}{l}\text { 1426598_at } \\
\text { 1422247_a_at }\end{array}$ & $\begin{array}{l}-2.33 \\
-1.35\end{array}$ \\
\hline Mid1 & midline 1 & BG073178 & negative regulation of microtubule depolymerization & 1438239_at & -1.99 \\
\hline Nepn & nephrocan & NM_025684 & $\begin{array}{l}\text { negative regulation of transforming growth factor beta } \\
\text { receptor signaling pathway }\end{array}$ & 1419065_at & -1.92 \\
\hline Myl3 & myosin, light polypeptide 3 & X67685 & & 1427768_s_at & -1.88 \\
\hline Sec23ip & Sec23 interacting protein & BE685845 & & 1439882_at & -1.8 \\
\hline Actc1 & actin, alpha, cardiac muscle 1 & NM_009608 & $\begin{array}{l}\text { apoptosis; muscle thin filament assembly; cardiac muscle } \\
\text { tissue morphogenesis }\end{array}$ & 1415927_at & -1.58 \\
\hline A230083H22Rik & RIKEN cDNA A230083H22 gene & AK018172 & & 1432198_at & -1.53 \\
\hline Ctla2a & cytotoxic T lymphocyte-associated protein 2 alpha & NM_007796 & & 1416811_s_at & $\begin{array}{l}-1.51 \\
-1.05\end{array}$ \\
\hline Adm & adrenomedullin & AV378441 & heart development; cell proliferation & 1447839_x_at & -1.43 \\
\hline Myl7 & myosin, light polypeptide 7 , regulatory & NM_022879 & & 1449071_at & -1.38 \\
\hline 3110040N11Rik & RIKEN cDNA 3110040N11 gene & AK019261 & & 1450972_at & -1.33 \\
\hline Myl4 & myosin, light polypeptide 4 & NM_010858 & & 1422580_at & -1.33 \\
\hline Rp/17 & ribosomal protein L17 & BF453369 & translation & 1453752_at & -1.28 \\
\hline Sc4mol & sterol-C4-methyl oxidase-like & AK005441 & steroid biosynthesis & 1423078_a_at & -1.24 \\
\hline 6720422M22Rik & RIKEN cDNA 6720422M22 gene & BB051012 & & 1437798_at & -1.21 \\
\hline Sfrp1 & secreted frizzled-related protein 1 & Bl658627 & somitogenesis; Wnt receptor signaling pathway & $\begin{array}{l}\text { 1460187_at } \\
1428136 \text { at }\end{array}$ & $\begin{array}{l}-1.21 \\
-0.7\end{array}$ \\
\hline Fosb & FBJ osteosarcoma oncogene B & NM_008036 & Regulation of transcription & 1422134_at & -1.17 \\
\hline Idi1 & isopentenyl-diphosphate delta isomerase & BC004801 & cholesterol biosynthesis & $\begin{array}{l}\text { 1423804_a_at } \\
\text { 1451122_at }\end{array}$ & $\begin{array}{l}-1.09 \\
-1.02\end{array}$ \\
\hline Insig1 & insulin induced gene 1 & BB005488 & cholesterol metabolic process & 1454671_at & -1.08 \\
\hline Ldlr & low density lipoprotein receptor & AF425607 & cholesterol metabolic process; & $\begin{array}{l}\text { 1421821_at } \\
\text { 1459403_at }\end{array}$ & $\begin{array}{l}-1.07 \\
-0.63\end{array}$ \\
\hline$A 2 m$ & alpha-2-macroglobulin & BB185854 & pregnancy & 1434719_at & -1.06 \\
\hline Ctla2b & cytotoxic T lymphocyte-associated protein 2 beta & BG064656 & & 1452352_at & -1.06 \\
\hline Cryab & crystallin, alpha B & AV016515 & muscle development; eye development & 1434369_a_at & -1.04 \\
\hline Myocd & myocardin & AF384055 & $\begin{array}{l}\text { vasculogenesis; heart development; regulation of } \\
\text { myoblast differentiation }\end{array}$ & 1425978_at & -1.02 \\
\hline Rassf5 & Ras association (RalGDS/AF-6) domain family member 5 & NM_018750 & apoptosis;cell cycle regulation & 1422638_s_at & -1.01 \\
\hline Trub1 & TruB pseudouridine (psi) synthase homolog 1 (E. coli) & AK011362 & tRNA processing & 1428281_at & -1 \\
\hline Myl9 & myosin, light polypeptide 9 , regulatory & AK007972 & & 1452670_at & -0.98 \\
\hline Shisa4 & shisa homolog 4 (Xenopus laevis) & BF468228 & & 1438426_at & -0.98 \\
\hline Cyp51 & cytochrome P450, family 51 & NM_020010 & cholesterol biosynthetic process & $\begin{array}{l}\text { 1422533_at } \\
\text { 1450646_at }\end{array}$ & $\begin{array}{l}-0.96 \\
-0.85\end{array}$ \\
\hline Fabp4 & fatty acid binding protein 4 , adipocyte & BC002148 & cholesterol homeostasis & $\begin{array}{l}\text { 1451263_a_at } \\
\text { 1417023_a_at }\end{array}$ & $\begin{array}{l}-0.96 \\
-0.54\end{array}$ \\
\hline Tnni1 & troponin I, skeletal, slow 1 & NM_021467 & ventricular cardiac muscle morphogenesis & 1450813_a_at & -0.95 \\
\hline $\begin{array}{l}\text { ENSMUSG000000 } \\
68790\end{array}$ & predicted gene, ENSMUSG00000068790 & BM195235 & & $\begin{array}{l}\text { 1452731_x_at } \\
\text { 1428301_at }\end{array}$ & $\begin{array}{l}-0.9 \\
-0.83\end{array}$ \\
\hline Gprc5b & G protein-coupled receptor, family C, group 5 , member B & BC020004 & signal transduction & 1451411_at & -0.9 \\
\hline Idh1 & isocitrate dehydrogenase $1(\mathrm{NADP}+)$, soluble & NM_010497 & glyoxylate cycle tricarboxylic acid cycle & 1422433_s_at & -0.89 \\
\hline \multirow[t]{2}{*}{ Slc30a1 } & solute carrier family 30 (zinc transporter), member 1 & BE685959 & zinc ion transport & 1436164_at & -0.89 \\
\hline & & AU042527 & & 1447096_at & -0.89 \\
\hline 2610528B01Rik & RIKEN cDNA 2610528B01 gene & AK012160 & & 1429232_at & -0.88 \\
\hline \multirow[t]{3}{*}{ Scd1 } & stearoyl-Coenzyme A desaturase 1 & NM_009127 & fatty acid biosynthetic process & $\begin{array}{l}\text { 1415964_at } \\
\text { 1415965_at }\end{array}$ & $\begin{array}{l}-0.87 \\
-0.48\end{array}$ \\
\hline & & $\mathrm{Bl} 134319$ & & 1442257_at & -0.86 \\
\hline & & BB235490 & & 1441050_at & -0.83 \\
\hline D14Ertd449e & DNA segment, Chr 14, ERATO Doi 449, expressed & BG072279 & & 1428738_a_at & -0.83 \\
\hline Rabif & $\mathrm{RAB}$ interacting factor & Al482417 & protein transport & 1457969_at & -0.83 \\
\hline LOC100040592 & similar to Hmgcs1 protein & BB705380 & & $\begin{array}{l}\text { 1433445_x_at } \\
\text { 1433444_at } \\
\text { 1433443_a_at }\end{array}$ & $\begin{array}{l}-0.83 \\
-0.78 \\
-0.66\end{array}$ \\
\hline Duxbl & double homeobox B-like & AV321065 & & 1445710_x_at & -0.82 \\
\hline Mef2c & myocyte enhancer factor $2 \mathrm{C}$ & BB280300 & $\begin{array}{l}\text { blood vessel development; osteoblast differentiation; } \\
\text { heart development transcription activator activity smooth } \\
\text { muscle cell differentiation }\end{array}$ & $\begin{array}{l}\text { 1424852_at } \\
\text { 1451507_at } \\
\text { 1421028_a_at }\end{array}$ & $\begin{array}{l}-0.79 \\
-0.71 \\
-0.44\end{array}$ \\
\hline
\end{tabular}


which led to the medial convergence and longitudinal extension of the lateral endoderm cell populations. Subsequently, these cells were found primarily in the lateral wall of the anterior intestinal portal (Fig 4 A, B left and right). A unique morphogenetic feature of the anterior intestinal portal is the asymmetric displacement of the endoderm cells in the plane of the epithelium (Franklin et al., 2008). This was observed in the wild type and Sox $17^{t /}$ mutant embryos in which cells from the left side of the portal were found on the floor (ventral wall) whereas those from the right side were found in the roof (dorsal wall) (Fig. 4 A, B left and right; Table 6). The Sox $17 \%$ embryos characteristically showed flattened neural folds and a shallow depression in the prospective foregut area at the initial phase of portal formation (Fig. 4C, Ohr). The lateral regions of the portal were wider apart, resulting in a short portal and with a broad entrance (Fig. 4C, 23hr). In addition, the lateral cell populations were mostly confined to the lateral walls and infrequently found asymmetrically on the dorsal or ventral wall of the portal (Fig. 4C, left and right; Table 6). Morphogenesis of the anterior intestinal portal in Sox $17^{-}$embryos is therefore defective with less convergence-extension and planar rotation of the anterior definitive endoderm.

\section{Loss of Sox17 leads to down-regulation of cardiac genes and abnormal morphogenesis of the heart tube}

Among the genes that were down-regulated in Sox17-null embryos, there was an over-representation of genes associated with heart development (Table 2). In particular, Myocd, a transcription factor expressed in the heart tube (Wang et al., 2001), is down-regulated significantly in early-somite stage Sox17/ embryos (Fig. 5A). Whole mount in situ hybridisation revealed that

TABLE 4

\section{GENES THAT WERE SIGNIFICANTLY DIFFERENTIALLY EXPRESSED IN SOX17/- EMBRYOS COMPARED TO WILD TYPE EMBRYOS AND IN SOX17-IRES-GFP TRANSFECTED HEPG2 CELLS COMPARED WITH GFP TRANSFECTED HEPG2 CELLS}

\begin{tabular}{|c|c|c|c|c|c|}
\hline Symbol (mouse/human) & Name & Affymetrix probe ID & $\begin{array}{l}\text { Sox17-/- mouse embryos } \\
\text { (Log } \text { Lold change) }^{2}\end{array}$ & Illumina target ID & $\begin{array}{l}\text { Sox17-IRES-GFP } \\
\text { HepG2 cells } \\
\text { (Log } \text { fold change) }\end{array}$ \\
\hline$A b c c 2 / A B C C 2^{*}$ & $\begin{array}{l}\text { ATP-binding cassette, sub-family C (CFTR/MRP), } \\
\text { member } 2\end{array}$ & 1450109_s_at & 1 & ILMN_9691 & -0.6043 \\
\hline$A d m / A D M^{*}$ & adrenomedullin & 1447839_x_at & -1.43 & ILMN_29514 & 1.009719 \\
\hline$A f p / A F P^{*}$ & alpha fetoprotein & $\begin{array}{l}\text { 1416646_at } \\
1436879 \text { __at } \\
1416645 \text { a_at }\end{array}$ & $\begin{array}{l}3.14 \\
2.96 \\
2.63\end{array}$ & ILMN_19039 & -0.20155 \\
\hline Agpat5/AGPAT5 & $\begin{array}{l}\text { 1-acylglycerol-3-phosphate O-acyltransferase } 5 \\
\text { (lysophosphatidic acid acyltransferase, epsilon) }\end{array}$ & 1453257_at & -0.44 & ILMN_9737 & -0.72299 \\
\hline Apoc2/APOC2* & apolipoprotein C-II & 1418069_at & 2.35 & ILMN_26723 & -0.35034 \\
\hline Bmp4/BMP4 & bone morphogenetic protein 4 & 1422912_at & 0.59 & ILMN_27187 & -0.46856 \\
\hline Cryab/CRYAB* & crystallin, alpha B & 1434369_a_at & -1.04 & ILMN_6827 & 1.910507 \\
\hline Eno3/ENO3 & enolase 3 , beta muscle & 1417951_at & -0.46 & ILMN_16651 & -0.36165 \\
\hline Eps8/EPS8 & epidermal growth factor receptor pathway substrate 8 & $\begin{array}{l}\text { 1422823_at } \\
\text { 1422824_s_at }\end{array}$ & $\begin{array}{l}0.52 \\
0.79\end{array}$ & ILMN_17717 & 0.556275 \\
\hline F10/F10* & coagulation factor $\mathrm{X}$ & 1449305_at & 0.65 & ILMN_138620 & -0.71965 \\
\hline $\mathrm{Fga} / F G A^{*}$ & fibrinogen, alpha polypeptide & 1424279_at & 1.31 & ILMN_11182 & -0.47527 \\
\hline$F g b / F G B^{*}$ & fibrinogen, $\mathrm{B}$ beta polypeptide & 1428079_at & 1.53 & ILMN_13882 & -0.32784 \\
\hline$F g g / F G G^{*}$ & fibrinogen, gamma polypeptide & 1416025_at & 1.99 & ILMN_26176 & -0.20352 \\
\hline Foxa3/FOXA3* & forkhead box A3 & 1431900_a_at & 0.42 & ILMN_22171 & -1.193 \\
\hline Ldlr $r L D L R^{\star}$ & low density lipoprotein receptor & $\begin{array}{l}\text { 1421821_at } \\
\text { 1459403_at }\end{array}$ & $\begin{array}{l}-1.07 \\
-0.63\end{array}$ & ILMN_10126 & 0.282144 \\
\hline Lgmn/LGMN & legumain & 1448883_at & 1.16 & ILMN_20242 & 0.620039 \\
\hline Lmna/LMNA* & $\operatorname{lamin} \mathrm{A}$ & 1421654_a_at & 0.39 & ILMN_12442 & -0.38805 \\
\hline Lrp8/LRP8 & $\begin{array}{l}\text { low density lipoprotein receptor-related protein } 8 \text {, } \\
\text { apolipoprotein e receptor }\end{array}$ & $\begin{array}{l}\text { 1440882_at } \\
\text { 1442347_at }\end{array}$ & $\begin{array}{l}-0.54 \\
-0.46\end{array}$ & ILMN_2030 & -0.42656 \\
\hline Mbl2/MBL2* & mannose-binding lectin (protein C) 2 & 1418787_at & 1.38 & ILMN_6942 & -1.53863 \\
\hline Nrp1/NRP1* & neuropilin 1 & 1457198_at & $\begin{array}{l}0.53 \\
0.54\end{array}$ & ILMN_17483 & -1.10432 \\
\hline Nsdhl/NSDHL & $N A D(P)$ dependent steroid dehydrogenase-like & 1416222_at & -0.63 & ILMN_13529 & -0.42729 \\
\hline$R b m 4 b / R B M 4 B^{*}$ & RNA binding motif protein 4B & 1430032_at & 0.41 & ILMN_29996 & -0.28508 \\
\hline Reep6/REEP6* & receptor accessory protein 6 & 1430128_a_at & 1.24 & ILMN_15192 & -0.64812 \\
\hline Sc4mol/SC4MOL & sterol-C4-methyl oxidase-like & 1423078_a_at & -1.24 & ILMN_2770 & -0.41272 \\
\hline Sec23ip/SEC23IP & Sec23 interacting protein & 1439882_at & -1.8 & ILMN_7522 & -0.4024 \\
\hline Slc16a10/SLC16A10 & $\begin{array}{l}\text { solute carrier family } 16 \text { (monocarboxylic acid transporters), } \\
\text { member } 10\end{array}$ & 1434592_at & 0.31 & ILMN_10556 & 0.425748 \\
\hline SIc2a2/SLC2A2* & $\begin{array}{l}\text { solute carrier family } 2 \text { (facilitated glucose transporter), } \\
\text { member } 2\end{array}$ & 1449067_at & 2.83 & ILMN_28285 & -1.20611 \\
\hline SIc30a1/SLC30A1* & solute carrier family 30 (zinc transporter), member 1 & 1436164_at & -0.89 & ILMN_5933 & 0.439786 \\
\hline SIc39a5/SLC39A5* & solute carrier family 39 (metal ion transporter), member 5 & 1429523_a_at & 0.78 & ILMN_14803 & -0.64595 \\
\hline Slco4c1/SLCO4C1* & solute carrier organic anion transporter family, member $4 \mathrm{C} 1$ & $\begin{array}{l}\text { 1460616_at } \\
\text { 1437870_at }\end{array}$ & $\begin{array}{l}1.29 \\
1.27\end{array}$ & ILMN_3183 & -0.37455 \\
\hline SluT/SLU7 & SLU7 splicing factor homolog (S. cerevisiae) & 1425488_at & 0.46 & ILMN_12938 & 0.927178 \\
\hline Zcchc14/ZCCHC14* & zinc finger, $\mathrm{CCHC}$ domain containing 14 & 1418170_a_at & 0.6 & ILMN_138708 & -0.63098 \\
\hline
\end{tabular}




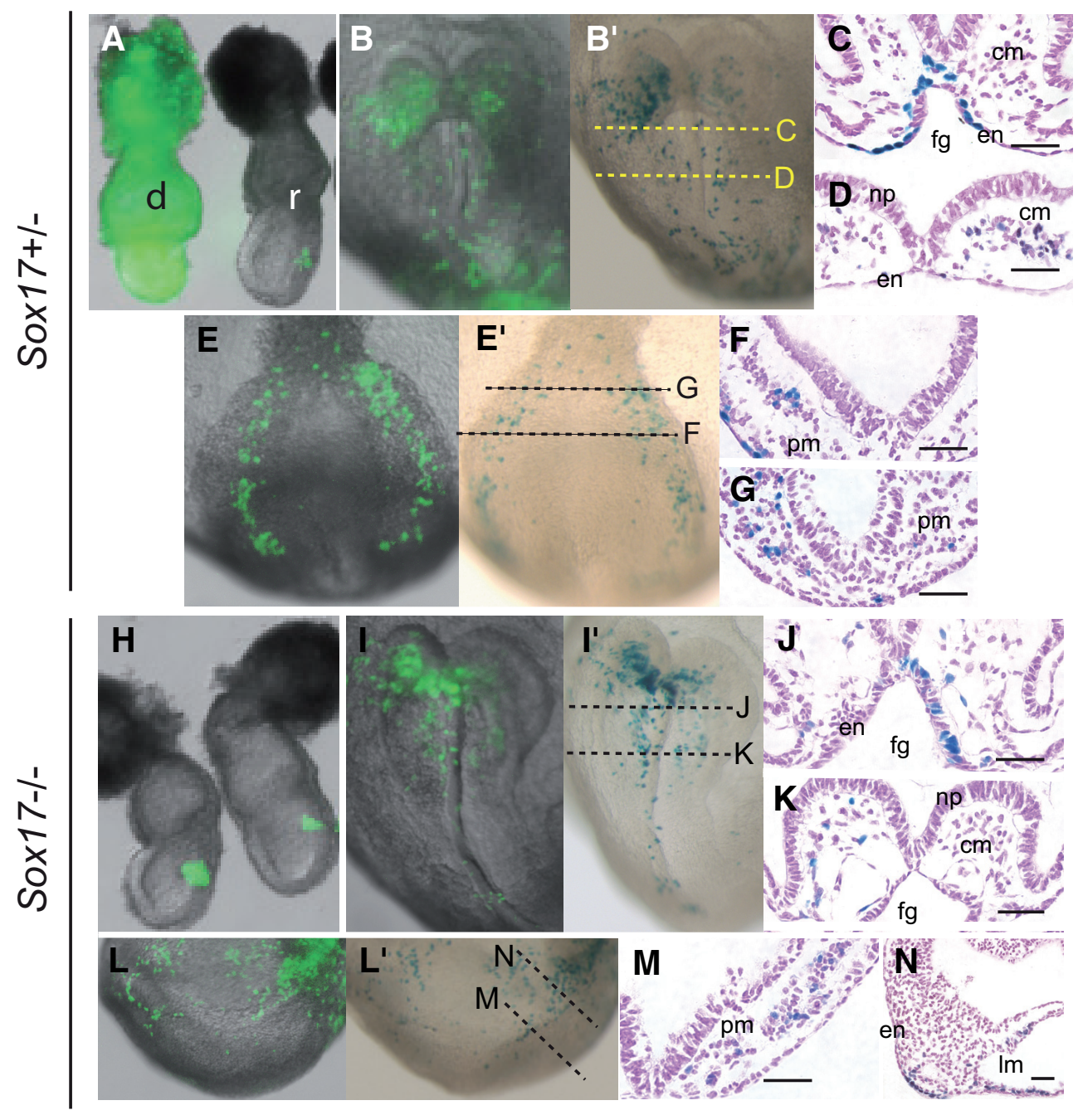

Fig. 3. Contribution of graft-derived cells in the recipient embryos. Transplantation of cells from the EGFP-expressing (A) Sox $17^{+/-}$donor (d) embryo and (H) Sox $17^{-1}$ donor embryos to the anterior region of the primitive streak of the wild type mid-streak stage recipient (r) embryo followed by visualization of the graftderived cells by fluorescence imaging (for EGFP: $B, E, I, L$ ) and X-gal staining (for lacZ: $\left.B^{\prime} E^{\prime}, I^{\prime}, L^{\prime}\right)$ in $\left(B, B^{\prime}, I, I^{\prime}\right)$ the anterior and $\left(E, E^{\prime}, L, L^{\prime}\right)$ posterior regions of the recipient embryo after 24 hours of in vitro development. Histology was performed on recipient embryos (in the same series of the transplantation but not necessarily of the specimens shown in $B^{\prime}, E^{\prime}, I^{\prime}$ and $\left.L^{\prime}\right)$. For orientation, planes of the histological sections are shown in $B^{\prime}, E^{\prime}, I^{\prime}$ and $L^{\prime}$. Graft-derived ( lacZ-expressing, visualized by blue $X$-gal staining reaction) ( $C$, $D, F, G)$ Sox17 $17^{+-}$cells and $(J, K, M, N)$ Sox $17^{+/-}$cells populate the endoderm (en) of the foregut portal (fg), and the cranial mesoderm $(\mathrm{cm})$ underneath the neural plate (np) in the anterior region; and the presomitic mesoderm (pm) and lateral plate mesoderm (Im) in the posterior region of the embryo. Scale bars, $100 \mu \mathrm{m}$.
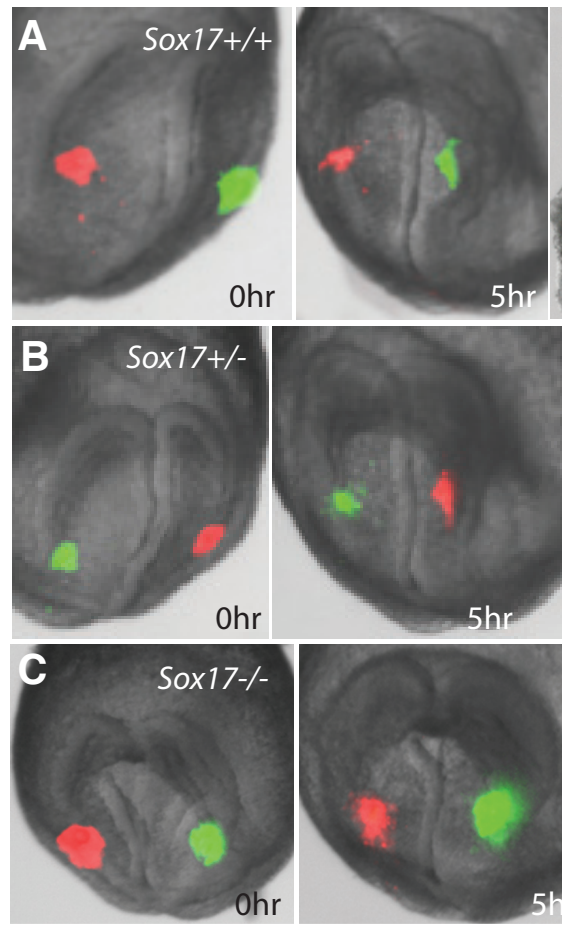
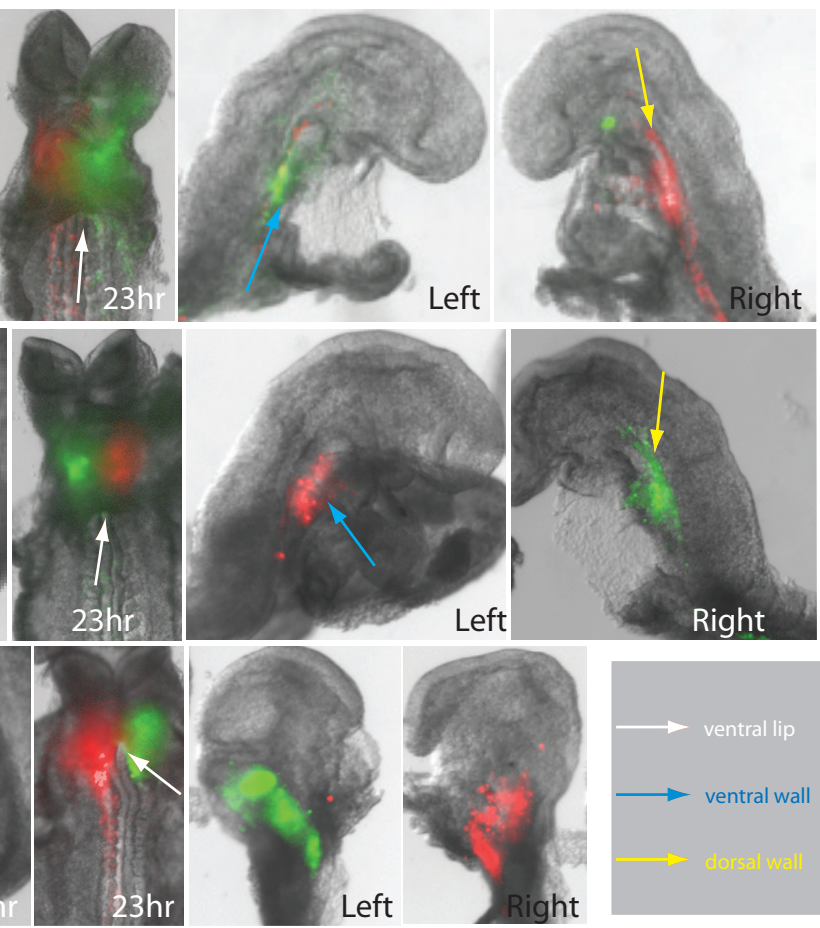

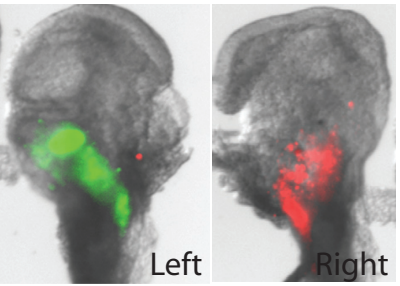

Fig. 4. Formation of the anterior intestinal portal. Distribution of contra-lateral cell population of the anterior definitive endoderm in the anterior intestinal portal at different time points (0, 5 and 23 hours) during its formation in (A) Sox $17^{+/+}$, (B) Sox $17^{+/-}$and (C) Sox $17^{-1-}$ embryos. Cells were labeled with DiO (green) and Dil (red) carbocyanine dye. Embryos were imaged intact during in vitro culture and were imaged after bisected into left and right halves at the end of culture to reveal the localization of the labelled cells. Arrows (see legend for colour code) point to the ventral lip, ventral wall and dorsal wall of the anterior intestinal portal. 
TABLE 5

\section{CONTRIBUTION OF THE ANTERIOR PRIMITIVE STREAK CELLS TO THE GERM LAYER DERIVATIVES DURING GASTRULATION AND EARLY ORGANOGENESIS}

\begin{tabular}{|c|c|c|c|c|}
\hline \multirow{2}{*}{$\begin{array}{l}\text { Donor genotypes } \\
\text { (no. of donor embryos) } \\
\text { Cellular contribution in } \\
\text { recipient embryos to: }\end{array}$} & \multicolumn{2}{|c|}{$\begin{array}{c}\text { Sox } 17^{+/+} \text {or Sox } 17^{+/-} \\
(n=15)\end{array}$} & \multicolumn{2}{|c|}{$\begin{array}{l}\text { Sox17/ } \\
(n=15)\end{array}$} \\
\hline & Cell count & $\%$ of total & Cell count & $\%$ of total \\
\hline Endoderm* & 290 & $8.1 \%$ & 163 & $4.1 \%$ \\
\hline Posterior neurectoderm ${ }^{\star}$ & 17 & $0.4 \%$ & 51 & $1.3 \%$ \\
\hline Cranial mesoderm & 361 & $10.1 \%$ & 545 & $13.7 \%$ \\
\hline Paraxial mesoderm & 460 & $12.8 \%$ & 444 & $11.2 \%$ \\
\hline Presomitic mesoderm* & 777 & $21.7 \%$ & 511 & $12.9 \%$ \\
\hline Lateral mesodem & 624 & $17.4 \%$ & 652 & $16.4 \%$ \\
\hline Heart mesoderm & 312 & $8.7 \%$ & 392 & $9.9 \%$ \\
\hline Extraembryonic mesoderm* & 716 & $20.8 \%$ & 1207 & $30.4 \%$ \\
\hline TOTAL & 3587 & & 3965 & \\
\hline Average & 239.1 & & 264.3 & \\
\hline
\end{tabular}

*Significant difference between genotypes by Chi-squared test at $\mathrm{P}<0.05$.

markers of the primary heart field (Myocd and Tbx5) and the secondary heart field $(/ s / \hbar)$ are expressed in the cardiogenic mesoderm of Sox $17^{-}$embryos at the early head-fold stage (Fig. $5 \mathrm{~B}, \mathrm{D}, \mathrm{F})$, suggesting that the heart precursors were present in the embryo and that the initial distribution of the cardiogenic mesoderm to the heart field is not affected by the loss of Sox17 in the endoderm. However, Myocd and Tbx5 expression was absent from the midline tissues in the primary heart field of the Sox $17^{/}$embryos (3/4), resulting in a hiatus in the cardiac crescent where the lateral population of the heart progenitors failed to unite medially (Fig. 5 C-G).

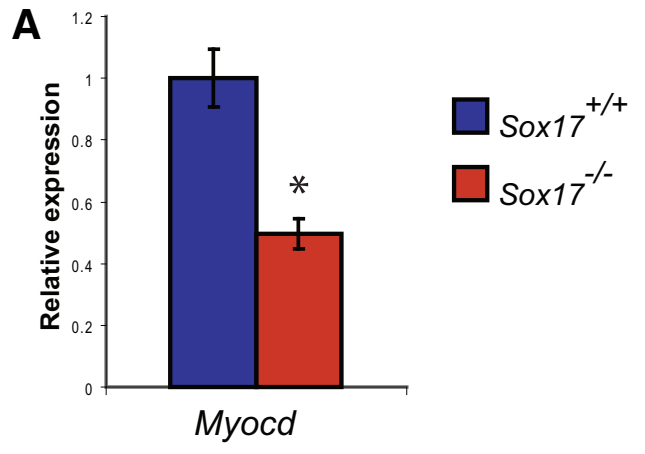

Fig. 5. Expression of heart genes in Sox17-/early head fold stage (pre-somite, E8.25) embryos revealed by whole mount in situ hybridization. (A) Down-regulation of Myocd in Sox 17\% embryos revealed by real time quantitative RT$P C R$. Error bars indicate standard error of the mean. $N=3$ for each assay ( ${ }^{*} P<0.05$ by $t$ test). Whole mount in situ hybridization of embryos showing the expression pattern of (B,C) Myocd and (D,E) Tbx5 in the cardiac crescent of (B) Sox17 $17^{++}$, (D) Sox17+/ - and (C,E) Sox17\% embryos. In Sox17-null embryos, expression of Tbx5 and Myocd is absent in the midline region of the cardiac crescent (arrows). $(\mathbf{F}, \mathbf{G})$ Expression of Isl1 is intact in the tissues in the secondary heart field of the Sox $17^{-1-}$ embryo.
TABLE 6

PATTERNS OF DISTRIBUTION OF CELLS ORIGINATING FROM THE LATERAL REGIONS OF THE ANTERIOR DEFINITIVE ENDODERM IN THE ANTERIOR INTESTINAL PORTAL

\begin{tabular}{|c|c|c|c|c|c|c|c|}
\hline \multirow{3}{*}{$\begin{array}{l}\text { Sox17 Genotype } \\
\text { of embryo }\end{array}$} & \multicolumn{7}{|c|}{ Distribution of labeled cells in the anterior intestinal portal ${ }^{+}$} \\
\hline & \multirow{2}{*}{$\begin{array}{c}\text { No of } \\
\text { embryos }\end{array}$} & \multicolumn{3}{|c|}{ Left side } & \multicolumn{3}{|c|}{ Right side } \\
\hline & & Ventral & Lateral & Dorsal & Ventral & Lateral & Dorsal \\
\hline \multirow[t]{4}{*}{$+/+$ or $+/-$} & 2 & = & 口 & & & & 口 \\
\hline & 6 & & 口 & & & [ & [ \\
\hline & 1 & 口 & - & & & घ & 口 \\
\hline & $1^{*}$ & 口 & 口 & & 口 & 口 & \\
\hline Total & 10 & 4 & 10 & & 1 & 8 & 9 \\
\hline \multirow[t]{4}{*}{$-/-$} & 1 & 口 & & & & E & [ \\
\hline & $1^{*}$ & & [ & & [ & [ & \\
\hline & 2 & & 口 & & & [ & \\
\hline & 1 & & 口 & & & 口 & \\
\hline Total & 5 & 1 & 4 & & 1 & 5 & 1 \\
\hline
\end{tabular}

DiO labeled cells; Dil labeled cells. + Three out of five null-mutant embryos showed localization of the labeled cells only to the lateral wall of the anterior intestinal portal. Only $1 / 5$ nullmutant as contrasted to $9 / 10$ wild type or heterozygous embryos showed proper asymmetrical distribution of labeled cells: significant difference at $\mathrm{P}<0.01$ by « 2 test. * One each of null-mutant and wild type/heterozygous showed atypical localization of labeled cells from right side to the ventral wall (floor) instead of dorsal wall (roof).

Examination the heart morphology of E8.5 Sox17-null embryos revealed abnormal heart tube phenotypes ranging from single heart tube that had not initiated looping (1/5) (Fig. 6B), incomplete union of the heart tube (1/5) (Fig. 6C) and the formation of two completely separated heart tubes (cardia bifida, 3/5) (Fig. 6D). The heart of Sox17 ${ }^{+/-}$embryos (not shown) was indistinguishable from that of the wild type (Fig. 6A). In the Sox17 mutant embryos the anterior intestinal portal was irregularly shaped and the floor crinkled extensively (Fig. 6 F, G, J), in contrast to the uniform contour in the wild type embryo (Fig. 6E). In Sox $17^{/-}$mutant embryo with incomplete fusion or separated heart tubes, the more caudal seg-

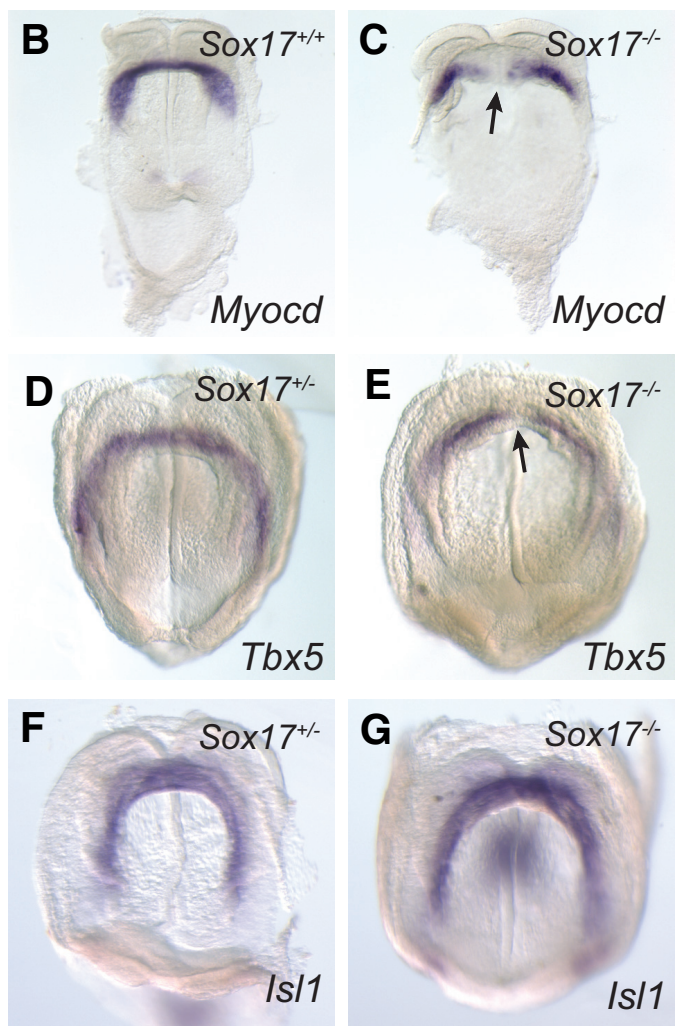
ment of the portal was open, resulting a wide ventral gap (Fig. 6 $\mathrm{K}, \mathrm{L}$ ), which in the wild type embryo was closed by this stage (Fig. $61)$. The defects of heart tube formation in the Sox17-null mutant embryos are therefore accompanied by the abnormal morphogenesis of the anterior intestinal portal in addition to the defects in cardiac mesoderm differentiation.

\section{Discussion}

Sox17 downstream genes and molecular pathways

Microarray analysis of wild-type and Sox 17-- embryos revealed changes in expression of genes that are associated primarily with the definitive endoderm (Nepn, Foxa3, and Hnf4a), as well as those that are expressed in both the extraembryonic visceral endoderm and the definitive endoderm (e.g.: Apolipoprotein genes, $T t r, A f p)$. Furthermore, there are 
changes in the expression of genes (e.g. heart development genes, cholesterol pathway genes) that are not associated with the endoderm.

To identify transcripts that are candidates for direct dependence on Sox17expression, we over-expressed Sox17in HepG2 cells. As the liver is derived from the definitive endoderm, we reasoned that HepG2 cells would provide a cellular environment comparable to the gut endoderm of the mouse embryo, where Sox17is normally expressed. Comparison of the results of the two array screens revealed a set of 21 genes whose changes in expression are consistent with either negative or positive regulation by Sox17. Analysis of publicly available gene expression data (http://biogps.gnf.org) revealed that 9 of these genes were specifically or predominantly expressed in adult and/or fetal liver ( $A f p$, Apoc2, F10, Fga, Fgb, Fgg, Mbl2, Reep6and S/c2a2). All of these genes were found in our micrarray study to be downregulated in the Sox17-overexpressing HepG2 cells and upregulated in Sox17/ embryos. These data, along with the significant overlap with $\mathrm{Hnf} 4 \mathrm{a}$ regulated genes, suggest the possibility that Sox 17 plays a role in repression of liver-specific gene expression. This is consistent with a role for Sox17 in maintaining definitive endoderm in the progenitor state, and the reported requirement for Sox17 in the delineation of specific foregut endoderm-derived lineages, including the gallbladder and bile duct (Spence et al., 2009; Uemura et al., 2010).

By comparing our mouse embryo and HepG2 micrarray expression data with ChIP data from mouse ES or XEN cells, we have identified a shortlist of six genes ( $A d m$, Fgb, Mbl2, Nrp1, $R b m 4 b, S / c 04 c 1)$ for which Sox17 influences their expression

A

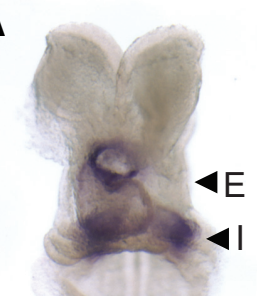

E
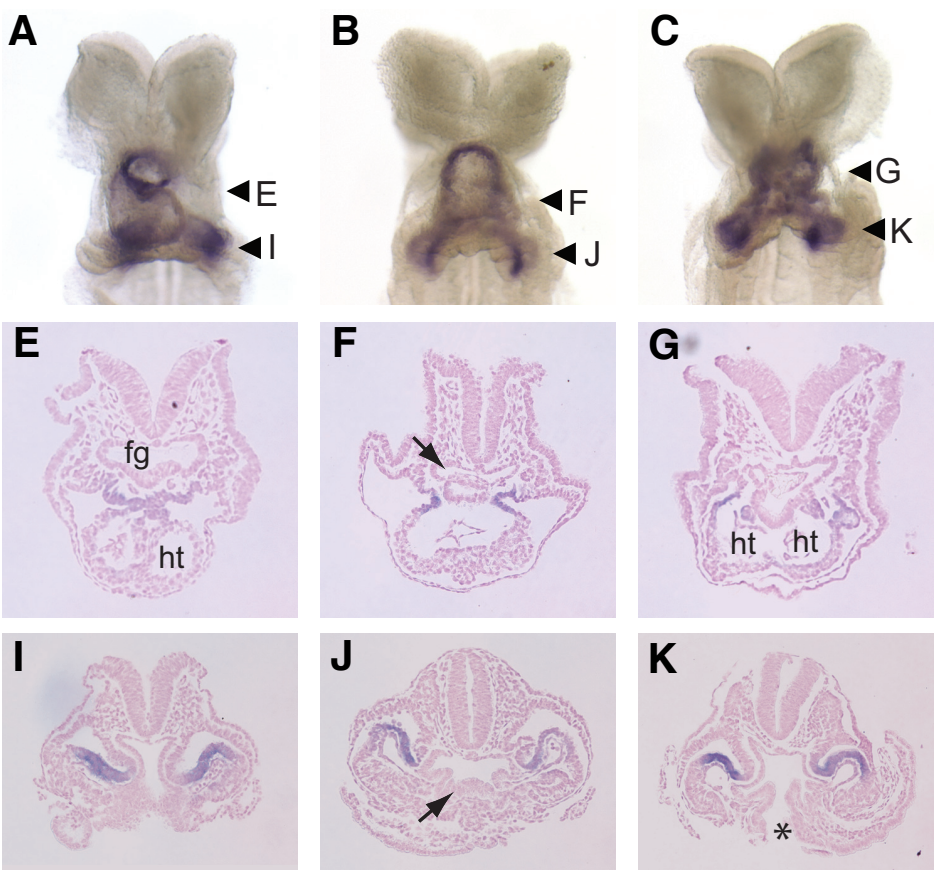

Fig. 6. Heart phenotype of E8.5 (7-8 somites) Sox 17-/- embryos. Wild type embryo shows a looping heart tube (A), whereas Sox17-- embryos display (B) un-looped heart tube, (C) partially united and (D) separate heart tube. Heart tissues are highlighted by Myocd expression by whole mount in situ hybridization $(A-D)$ and in histological preparations ( $E-L$, planes of sectioning indicated by arrowheads in A-D). The foregut of Sox 17-- embryo has an abnormal shape (F, arrow) and an expanded corrugated floor ( $J$, arrow) and opens ventrally ( $K, L$ : asterisk) in the posterior region of the foregut of embryos with bifid heart tube. ht: heart tube, fg: foregut.
D

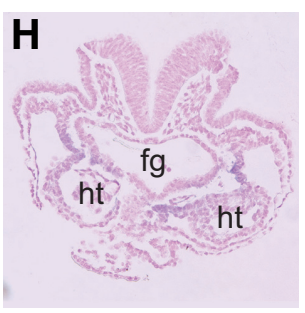

$\mathbf{L}$

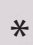

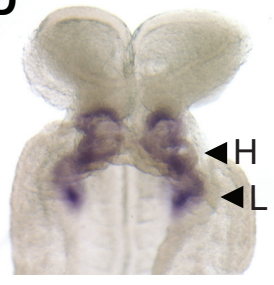

and there is evidence for binding of Sox17 protein to regulatory regions. These genes are diverse in function and expression and represent strong candidates for Sox17 transcriptional target genes.

\section{Loss of Sox17 function impairs the allocation of endoderm cells}

Although the Sox17-mutant phenotype indicates a role in the development of the definitive endoderm, several lines of evidence also point to a requirement of Sox17in the differentiation of extraembryonic endoderm. In mouse ESC, enforced expression ofn Sox 17 promotes the differentiation of extraembryonic endoderm, whereas Sox17-null ES cells maintain the expression of pluripotency genes and fail to differentiate into extraembryonic endoderm. Stem cells with extraembryonic endoderm properties (XEN cells) cannot be generated from Sox17-null embryos (Niakan et al., 2010). In contrast, in human ESC, progenitors with stable characteristics of definitive endoderm can be generated by constitutive expression of Sox17, whereas expression of another Group F Sox factor, Sox7, produces cells with more restricted potential reminiscent of the extraembryonic endoderm (Seguin et al., 2008). Transcriptional profiling of SOX17 and SOX7 overexpressing human ESCs revealed that the sets of genes that were specifically upregulated by either SOX17 or SOX7 were far greater than the set of genes that was upregulated by both, indicating unique, tissue-specific roles for the two transcription factors. In agreement with these findings, our microarray data do not support a role for Sox17in promoting extraembryonic endoderm differentiation in mouse embryos. Instead, our data show up-regulation of extraembryonic gene expression in Sox17-null embryos, consistent with apparent replacement of definitive endoderm with visceral endoderm-like cells (Kanai-Azuma et al., 2002).

Sox17-null ES cells are unable to contribute significantly to the definitive endoderm of the gut in the presence of wild type cells in the chimera (Kanai-Azuma et al., 2002). Cell transplantation experiments performed in the present study further show that cells of the Sox $17^{-1}$ anterior primitive streak, where the endoderm progenitors are localised (Lawson et al., 1991), are less efficient in contributing descendants to the host embryonic gut. The chimera and transplantation studies seem to show that, in addition to the maintenance of the lineage, Sox17function may also play a role in, but not be essential for, the allocation of progenitors of the endoderm lineage. The elevated level of expression of many visceral endoderm genes in the Sox17-null embryos might result from the increased presence of extraembryonic endoderm which takes 
the place of the gut endoderm cells. This may be the result of not only the prevalence of apoptosis and reduced proliferative activity but also of the compromised ability of the mutant cells to contribute to the definitive endoderm.

\section{Morphogenesis of the embryonic foregut and the heart tube is dependent on Sox17 function}

Development of the embryonic foregut is initiated by the formation of the anterior intestinal portal beginning with the invagination of the anterior definitive endoderm underneath the head folds, accompanied by the longitudinal extension of the medial regions and the convergence of the lateral parts of the endoderm layer (Franklin et al., 2008). An intriguing feature of the morphogenesis of the portal is the pattern of movement of the contra-lateral endoderm populations of the prospective foregut. While these populations are undergoing longitudinal extension, they are also displaced asymmetrically along the wall of the portal: cells on the right populate the right and dorsal (roof) sides while cells on the left populate the left and ventral (floor) of the portal. The asymmetrical distribution of contra-lateral endoderm cells is accomplished by the directional relocation of cells within the epithelium that lines the portal and not due to the "rotation" of the foregut. However, the asymmetry of cell displacement corresponds with the laterality of subsequent rotation (left to ventral and right to dorsal) of the lower foregut. Sox17-null embryos form an anterior intestinal portal which is shorter and wider than the wild type counterpart, with excess folding of the floor and a split posterior ventral lip of the portal. Tracking the morphogenetic movement of anterior definitive endoderm in the null mutant embryo further revealed a much reduced longitudinal extension and medial convergence of the lateral endoderm, culminating in the distribution of these cells to wide lateral domain in the portal and very restricted rotational displacement.

Heart defects were not reported in the initial analysis of the Sox17-null phenotype (Kanai-Azuma et al., 2002). A subsequent study revealed that the heart of the mutant embryo displayed defects in the looping of the heart tube (Sakamoto et al., 2007). Our study further shows that Sox17-null mutant embryos display additional and more severe defects of the heart tube: lack of union of the cardiac precursors from the contra-lateral part of the cardiac crescent and bifid heart tubes. One possible cause of the difference in the manifestation of heart defects in our study and that of Sakamoto et al. (2007) is the difference in background. Whereas in the latter study, the mice were maintained on a mixed 129/Sv $X$ C57BL/6 background, our mice have been maintained on a predominantly 129/Sv background. A precedent for the effect of genetic background on the heart defects is seen in Fibronectin 1 mutants which display less severe heart phenotype with an increasing contribution of C57/BL6 over the 129/Sv background (George et al., 1997).

The formation of a wide portal with a ventral hiatus and the lack of asymmetrical displacement of the cells in the portal could be the morphogenetic factors underlying the incomplete fusion and lack of looping of the heart tube. Similar cardia bifida phenotypes found in other mouse and Zebrafish mutants are also accompanied by defects in foregut development, such as absence or reduction of foregut endoderm and incomplete closure of the foregut pocket (Alexander et al., 1999; Kuo et al., 1997; Li et al., 2004; Molkentin et al., 1997; Reiter et al., 1999; Roebroek et al.,
1998). It is not known whether the heart tube defects are due to the abnormal morphogenesis of the anterior intestinal portal and whether, in a broader context, the laterality in tissue movement in the anterior intestinal portal may predispose the direction of heart looping and the left-right asymmetry of the heart and the digestive tract.

\section{Sox17 activity in the endoderm influences cardiac cell differ- entiation}

In the mouse embryo, the cardiac cells are derived from two sources of progenitor cells: the primary and the secondary heart field. The primary heart field, consisting of Tbx5- and Myocdexpressing cells contributes to the left ventricle and atria. The secondary heart field, populating by /s/1-expressing cells, contributes to the outflow tract, right ventricle and atria and the pharyngeal mesoderm (Buckingham et al., 2005). Expression profiling analysis reveals that loss of Sox17 is associated with the downregulation of $M y o c d$ expression. The heart-specific transcription factors Myocd, Tbx5 and /s/1 are expressed in the cardiac crescent. However, Myocdand Tbx5are specifically down-regulated in the tissues at the vertex of the crescent. The domain where Myocd and Tbx5 expression is lacking corresponds to the region of defective union of the lateral cardiac progenitors in the midline. The cardia bifida phenotype in the absence of Sox17is therefore most likely to be initiated by a failure in the fusion of the cardiac crescent at the midline leading to the formation of two separate lateral heart tubes. Our findings therefore suggest that Sox17 activity in the definitive endoderm is required for the induction Myocd-expressing cardiogenic mesoderm in a specific population of cells in the primary heart field that form the atria and part of the ventricle.

Sox17has been shown to act in a non-cell autonomous manner in eliciting cardiac differentiation in mouse ES cells. Inhibition of Sox17 in mouse ES cells leads to a suppression of cardiac differentiation (Liu et al., 2007). The expression of Sox17 in the foregut endoderm could therefore be required for the induction of heart-specific genes in the embryo. This may occur either by direct regulation of genes encoding signalling molecules or antagonists by Sox 17, or indirectly with Sox17playing a role in the maintenance or differentiation of the definitive endoderm, which then expresses the morphogenetic signals for heart development. Consistent with the non-cell autonomous role of Sox17in heart development, overexpressed Sox17in the pluripotent fibroblast cell line C3H10T1/2 does not induce Myocdexpression (our unpublished data). On the other hand, co-culture of C3H10T1/2 with HepG2 cells does induce Myocd expression in the C3H10T1/2 cells, suggesting that the endoderm derived HepG2 cells are secreting a cardiac-inducing factor into the media. This is consistent with Sox17 playing an indirect role in heart induction. However, transfection of a Sox17 expression construct into the HepG2 cells does not result in increased Myocd expression in co-cultured C3H10T1/2 cells (F. Kruiswijk, DAFL and PPLT unpublished data). In this case, the HepG2 cells are already primed to express the cardiac-inducing factor independently of Sox17expression.

\section{Materials and Methods}

\section{Mouse strains and genotyping}

Sox17mutant mice (Kanai-Azuma et al., 2002) were maintained on a $129 / \mathrm{Sv}$ background. Heterozygous Sox $17^{+/}$mice were inter-crossed to 
generate wild type embryos, and heterozygous and homozygous mutant embryos for phenotypic analysis, expression studies and embryological experimentation. For testing the lineage potential of Sox $1 \%$ embryonic cells in the cell grafting experiment, Sox $17^{+/}$mice were crossed with transgenic mice $(\mathrm{H} 253)$ that co-express two transgenes (Hmgcr-n/s-lacZand pCAGG-EGFP) widely in embryonic tissues (Hadjantonakis et al., 1998; Kinder etal., 2001; Tam and Tan, 1992) to derive a line of Sox17//;H253 mice (SGX). The SGX mice were inter-crossed to generate embryos of different Sox17genotypes that express the transgenic reporters, so that the cells harvested from these embryos can be tracked during the course of the cell grafting experiment.

\section{Microarray analyses}

Total RNA from embryonic specimens was isolated using the RNeasy Micro Kit (QIAGEN) according to the manufacturer's instructions. RNA was isolated from two pairs of somite-number matched (4-5 somites) Sox17/ mutant and wild type embryos. The quality and quantity of the isolated RNAs were assessed on an Agilent Bioanalyser. RNA probes were amplified and labelled using the Affymetrix two-cycle process. Each RNA probe was hybridised to two or three Affymetrix GeneChip mouse genome 4302.0 arrays, comprising all the known and predicted genes in the mouse genome. The arrays were read with an Affymetrix GS3000 scanner and raw data imported into Chipster v 1.4.4 (http://chipster.csc.fi) for normalization (RMA) and statistical analysis by linear modelling using LIMMA (significance at $\mathrm{P}<0.05$ ), taking into account biological and technical replicates. Analysis of gene ontology was carried out within Chipster using a hypergeometric test for over-representation of terms.

HepG2 (Human hepatocellular carcinoma) cells were maintained in $\mathrm{DMEM}+10 \% \mathrm{FCS}$. Prior to transfection, approximately $2 \times 10^{6}$ cells were seeded into T75-flasks. One day later, the HepG2 cultures were transiently transfected with $8 \mu \mathrm{g}$ of pCMV-Sox 17 -EGFP or CMV-EGFP control and 24 $\mu$ I FuGENE6 (Roche). After 48 hours the EGFP expressing cells were isolated using the flow cytometry (FACSVantage cell sorter). Total RNA was extracted from the cell pellets using the RNeasy Mini Kit (QIAGEN) according to the manufacturer's protocol. RNA samples from three independent groups of transfected cells were amplified, labelled and hybridised to Illumina Sentrix® Human-6 v2 Expression BeadChips that cover the human genome. The arrays were analysed with the Illumina BeadStation 500 reader. Beadstudio was used to normalize the data (cubic spline) and identify transcripts whose expression level had significantly changed (Illumina Custom test, $\mathrm{p}<0.01$ ).

\section{Quantitative real-time $R T$-PCR}

RNA samples from Sox17mutant and wild type embryos (4-5 somites) were reverse transcribed into cDNA using the SuperScript III First-Strand Synthesis System (Invitrogen). Real-time quantitative RT-PCR was performed on Rotor-Gene thermocyclers (Corbett Research) using QuantiTect SYBR Green (QIAGEN) or Platinum Taq (Invitrogen). Details of PCR primers are given in Supplementary Tables S6 and S7.

\section{Generation of riboprobes}

To generate a plasmid from which to make a Myocd whole mount in situ hybridisation probe, a fragment was amplified from mouse E8.5 cDNA using PfuDNA polymerase (Roche). Primer sequences for generating the 750bp probe were forward: 5'-TGGGCTAGACTCTGAGAAGGAC -3' and reverse: 5'-TGGGTGATATCTGAAACTGCTG-3'. The amplified fragments were subsequently cloned into PGEM-T (Promega) downstream of the T7 promoter. The $T b \times 5$ antisense probe has been described previously (Chapman et al., 1996). The /s/1 probe was kindly provided by Gerhard Przemeck (Helmholtz Zentrum München). For the generation of antisense RNA probes from linearized cDNA clones the DIG RNA labelling kit (Roche) has been used according to the manufacturer's instructions.

Whole mount in situ hybridisation

For whole mount in situhybridisations embryos were fixed in 4\% PFA in PBS over night, dehydrated in methanol and stored at $-20^{\circ} \mathrm{C}$ until usage. Whole mount in situhybridisations were performed as described previously (Chapman et al., 1996; Davidson et al., 1999). In brief, embryos were rehydrated in PBT (PBS plus $0.1 \%$ Tween-20), bleached with $6 \%$ hydrogen peroxide in PBT for 30min, washed in PBT, refixed in 4\% PFA in PBS containing $0.2 \%$ glutaraldehyde for $20 \mathrm{~min}$ and washed in PBT. Hybridisations with DIG-labelled antisense probes (1:200) were performed in hybridisation buffer ( $50 \%$ formamide, $5 \times$ SSC pH $4.5,1 \%$ SDS, $50 \mu \mathrm{g} / \mathrm{ml} \mathrm{Heparin)} \mathrm{at}$ $70^{\circ} \mathrm{C}$ over night. After two washes each in $2 \times$ SSC, $0.1 \%$ SDS and $0.2 \mathrm{x}$ SSC, $0.1 \%$ SDS at $70^{\circ} \mathrm{C}$, embryos were washed 3 times in MABT (100mM maleic acid $\mathrm{pH} 7.5,150 \mathrm{mM} \mathrm{NaCl}, 1 \%$ Tween-20, $2 \mathrm{mM}$ Levamisole). Embryos were blocked in 2\% blocking reagent (Roche) in MABT for $1 \mathrm{~h}$, in $2 \%$ blocking reagent with $20 \%$ FCS in MABT for $1-3 \mathrm{~h}$ and incubated with alkaline phosphatase coupled anti-DIG antibody (Roche) (1:2000) in $2 \%$ blocking reagent with $20 \%$ FCS in MABT at $4^{\circ} \mathrm{C}$ over night. After extensive washing in MABT for 1-3 days the embryos were washed twice in $2 \mathrm{mM}$ Levamisole, $0.1 \%$ Tween-20. BM purple AP substrate (Roche) was used for subsequent alkaline phosphatase staining. The embryos were kept in 4\% PFA. After whole mount in situhybridisations the embryos were dehydrated, embedded in paraffin wax and sectioned at $7 \mu \mathrm{m}$. The sections were counterstained with nuclear fast red and mounted using Canada balsam.

\section{$X$-Gal staining of embryos}

Embryos were washed twice in PBS, fixed in 4\% PFA in PBS for 5 min and washed again twice in PBS. In order to detect lac $Z$ the embryos were stained in X-gal [5-bromo-5-chloro-3-indoyl- $\beta$-D-galactopyranoside] staining solution $\left(1 \mathrm{mg} / \mathrm{ml} \mathrm{X-gal,} 5 \mathrm{mM} \mathrm{K}_{3} \mathrm{Fe}(\mathrm{CN})_{6}, 5 \mathrm{mM} \mathrm{K} 4 \mathrm{Fe}(\mathrm{CN})_{6}, 2 \mathrm{mM}\right.$ $\mathrm{MgCl}_{2}, 0.01 \%$ Tween-20, $0.2 \%$ PFA in PBS) for $40 \mathrm{~min}$ at $37^{\circ} \mathrm{C}$. Afterwards the embryos were rinsed twice in PBS and fixed in 4\% PFA in PBS over night. The stained embryos were processed for wax histology and the relative contribution of the graft-derived cells to various types of germ layer derivatives evaluated by scoring the number of $\mathrm{X}$-gal stained cells in serial sections of the recipient embryos.

\section{Cell transplantation}

Embryos from SGX mating were collected at the E7.0 mid-streak stage. GFP positive embryos were selected as donors for transplantation. Tissue fragments from the anterior primitive streak of these embryos were isolated and further dissociated into small clumps of cells. The cell clumps were then transplanted to the anterior primitive streak of stage-matched wild type (ARC/s) embryos using a Leica micromanipulator. The remaining part of the embryo was collected for PCR genotyping. After grafting, the recipient embryos were checked by fluorescence microscopy for the correct placement of the transplanted cells. Embryos were cultured for 24-28h in a medium made up of $75 \%$ heat-inactivated rat serum and $25 \%$ Dulbecco's modified Eagle medium at $37^{\circ} \mathrm{C}$ in glass bottles rotating at 30 RPM with a continuously replenished gas phase of $5 \% \mathrm{CO}_{2}, 20 \% \mathrm{O}_{2}$ and $75 \% \mathrm{~N}_{2}$ (Sturm and Tam, 1993). At the end of culture, recipient embryos were imaged by fluorescence photomicroscopy to visualise and record the distribution of the EGFP-expressing cells. Embryos containing EGFPexpressing graft-derived cells were then fixed in $4 \%$ PFA and stained in $\mathrm{X}$-gal staining solution to detect lac $Z$ expression.

\section{Dye labelling of the foregut endoderm}

E7.0 mid-streak-stage embryos were harvested from pregnant mice generated by inter-crossing Sox $17^{+/}$mice. Embryos were dissected from the decidua and the Reichert's membrane was removed. Embryos were selected by somite numbers to ensure stage-matching (1-3 somites) between groups of different Sox17genotypes. They were kept in 100\% rat serum in a $5 \% \mathrm{CO}^{2}$ incubator at $37^{\circ} \mathrm{C}$ prior to micro-manipulation. For dye labelling, cells in the anterior definitive endoderm were painted with carbocyanine dyes: DiO (D275, Molecular Probes) and CM-Dil (C-7001, Molecular Probes) (Bildsoe et al., 2007). In each embryo, around 100-150 cells each were labelled with one of the two dyes in order to reveal the 
relative spatial distribution of different cell populations and to track their morphogenetic movement during foregut morphogenesis. Following dye labelling, embryos were cultured for 12 hours under the same conditions as the cell grafting studies. Labelled embryos were imaged by fluorescence microscopy within 1 hour after labelling to ascertain the site of labelling. The embryos were re-imaged at the end of a 12-hour culture period to visualise the distribution of labelled cells in the embryonic gut. Photographs were taken using a Leica MZ16 microscope with a SPOT Advanced digital camera and fluorescent and bright field images were digitally edited and merged with the SPOT 4.0 software and Adobe Photoshop 7.0. The yolk sac of the embryo was collected to prepare the DNA for genotyping.

\section{Acknowledgements}

We acknowledge the support of a Deutscher Akademischer Austauschdienst Fellowship (SP) and studentship from University of Applied Sciences, Mannheim (GT). DL is a Kimberly-Clark Research Fellow and PT is a NMHRC Senior Principal Research Fellow. This work is supported by NHMRC project grant 321704. Our thanks also to Mr. James Fairfax.

\section{References}

ALEXANDER, J., ROTHENBERG, M., HENRY, G.L. and STAINIER, D.Y. (1999). casanova plays an early and essential role in endoderm formation in zebrafish. Dev Biol215: 343-357.

BILDSOE, H., FRANKLIN, V. and TAM, P.P.L. (2007). Fate-Mapping Technique: Using Carbocyanine Dyes for Vital Labeling of Cells in Gastrula-Stage Mouse Embryos Cultured In vitro. Cold Spring Harb Protoc 2007: db.

BUCKINGHAM, M., MEILHAC, S. and ZAFFRAN, S. (2005). Building the mammalian heart from two sources of myocardial cells. Nat Rev Genet 6: 826-835.

CHAPMAN, D.L., GARVEY, N., HANCOCK, S., ALEXIOU, M., AGULNIK, S.I., GIBSON-BROWN, J.J., CEBRA-THOMAS, J., BOLLAG, R.J., SILVER, L.M. and PAPAIOANNOU, V.E. (1996). Expression of the T-box family genes, Tbx1Tbx5, during early mouse development. Dev Dyn 206: 379-390.

CLEMENTS, D., CAMELEYRE, I. and WOODLAND, H.R. (2003). Redundant early and overlapping larval roles of Xsox17 subgroup genes in Xenopus endoderm development. Mech Dev 120: 337-348.

DAVIDSON, B.P., KINDER, S.J., STEINER, K., SCHOENWOLF, G.C. and TAM, P.P. (1999). Impact of node ablation on the morphogenesis of the body axis and the lateral asymmetry of the mouse embryo during early organogenesis. Dev Bio/211: 11-26.

FRANKLIN, V., KHOO, P.L., BILDSOE, H., WONG, N., LEWIS, S. and TAM, P.P. (2008). Regionalisation of the endoderm progenitors and morphogenesis of the gut portals of the mouse embryo. Mech Dev 125: 587-600.

GEORGE, E.L., BALDWIN, H.S. and HYNES, R.O. (1997). Fibronectins are essential for heart and blood vessel morphogenesis but are dispensable for initial specification of precursor cells. Blood 90: 3073-3081.

HADJANTONAKIS, A.K., GERTSENSTEIN, M., IKAWA, M., OKABE, M. and NAGY, A. (1998). Generating green fluorescent mice by germline transmission of green fluorescent ES cells. Mech Dev 76: 79-90.

HARMON, E.B., KO, A.H. and KIM, S.K. (2002). Hedgehog signaling in gastrointestinal development and disease. Curr Mol Med2: 67-82.

HART, A.H., HARTLEY, L., SOURRIS, K., STADLER, E.S., LI, R., STANLEY, E.G., TAM, P.P., ELEFANTY, A.G. and ROBB, L. (2002). Mixl1 is required for axial mesendoderm morphogenesis and patterning in the murine embryo. Development 129: 3597-3608.

HOU, J., CHARTERS, A.M., LEE, S.C., ZHAO, Y., WU, M.K., JONES, S.J., MARRA, M.A. and HOODLESS, P.A. (2007). A systematic screen for genes expressed in definitive endoderm by Serial Analysis of Gene Expression (SAGE). BMC Dev Bio/7: 92.

IYER, V.R., EISEN, M.B., ROSS, D.T., SCHULER, G., MOORE, T., LEE, J.C.F., TRENT, J.M., STAUDT, L.M., HUDSON, J., BOGUSKI, M.S., LASHKARI, D., SHALON, D., BOTSTEIN, D. and BROWN, P.O. (1999). The Transcriptional Program in the Response of Human Fibroblasts to Serum. Science283: 83-87.
KANAI-AZUMA, M., KANAI, Y., GAD, J.M., TAJIMA, Y., TAYA, C., KUROHMARU M., SANAI, Y., YONEKAWA, H., YAZAKI, K., TAM, P.P. and HAYASHI, Y. (2002). Depletion of definitive gut endoderm in Sox17-null mutant mice. Deve/opment 129: 2367-2379.

KIEFER, J.C. (2003). Molecular mechanisms of early gut organogenesis: a primer on development of the digestive tract. Dev Dyn, 228: 287-291.

KINDER, S.J., TAN, S.S. and TAM, P.P. (2000). Cell grafting and fate mapping of the early-somite-stage mouse embryo. Methods Mol Biol 135: 425-437.

KINDER, S.J., TSANG, T.E., WAKAMIYA, M., SASAKI, H., BEHRINGER, R.R. NAGY, A. and TAM, P.P. (2001). The organizer of the mouse gastrula is composed of a dynamic population of progenitor cells for the axial mesoderm. Development 128: 3623-3634.

KUO, C.T., MORRISEY, E.E., ANANDAPPA, R., SIGRIST, K., LU, M.M., PARMACEK, M.S., SOUDAIS, C. and LEIDEN, J.M. (1997). GATA4 transcription factor is required for ventral morphogenesis and heart tube formation. Genes Dev 11: 1048-1060.

LAUBNER, D., BREITLING, R. and ADAMSKI, J. (2003). Embryonic expression of cholesterogenic genes is restricted to distinct domains and colocalizes with apoptotic regions in mice. Brain Res Mol Brain Res 115: 87-92.

LAWSON, K.A., MENESES, J.J. and PEDERSEN, R.A. (1991). Clonal analysis of epiblast fate during germ layer formation in the mouse embryo. Development 113: 891-911.

LEWIS, S.L., TAM, P.P. (2006). Definitive endoderm of the mouse embryo: formation, cell fates, and morphogenetic function. Dev Dyn 235: 2315-2329.

LI, S., ZHOU, D., LU, M.M. and MORRISEY, E.E. (2004). Advanced cardiac morphogenesis does not require heart tube fusion. Science 305: 1619-1622.

LIU, Y., ASAKURA, M., INOUE, H., NAKAMURA, T., SANO, M., NIU, Z., CHEN, M., SCHWARTZ, R.J. and SCHNEIDER, M.D. (2007). Sox17 is essential for the specification of cardiac mesoderm in embryonic stem cells. Proc Nat/ Acad Sci USA 104: 3859-3864.

LUNDE, K., BELTING, H.G. and DRIEVER, W. (2004). Zebrafish pou5f1/pou2, homolog of mammalian Oct4, functions in the endoderm specification cascade. Curr Bio/14: 48-55.

MARIJANOVIC, Z., LAUBNER, D., MOLLER, G., GEGE, C., HUSEN, B., ADAMSKI, J. and BREITLING, R. (2003). Closing the gap: identification of human 3ketosteroid reductase, the last unknown enzyme of mammalian cholesterol biosynthesis. Mol Endocrino/17: 1715-1725.

MOLKENTIN, J.D., LIN, Q., DUNCAN, S.A. and OLSON, E.N. (1997). Requirement of the transcription factor GATA4 for heart tube formation and ventral morphogenesis. Genes Dev 11: 1061-1072.

NIAKAN, K.K., JI, H., MAEHR, R., VOKES, S.A., RODOLFA, K.T., SHERWOOD, R.I., YAMAKI, M., DIMOS, J.T., CHEN, A.E., MELTON, D.A., MCMAHON, A.P. and EGGAN, K. (2010). Sox17 promotes differentiation in mouse embryonic stem cells by directly regulating extraembryonic gene expression and indirectly antagonizing self-renewal. Genes Dev 24: 312-326.

PEARCE, J.J.H., EVANS, M.J. (1999). Mml, a mouse Mix-like gene expressed in the primitive streak. Mech. Dev. 87: 189-192.

QU, X.B., PAN, J., ZHANG, C. and HUANG, S.Y. (2008). Sox17 facilitates the differentiation of mouse embryonic stem cells into primitive and definitive endoderm in vitro. Dev Growth Differ 50: 585-593.

REIM, G., MIZOGUCHI, T., STAINIER, D.Y., KIKUCHI, Y. and BRAND, M. (2004) The POU domain protein spg (pou2/Oct4) is essential for endoderm formation in cooperation with the HMG domain protein casanova. Dev Cel/6: 91-101.

REITER, J.F., ALEXANDER, J., RODAWAY, A., YELON, D., PATIENT, R., HOLDER, N. and STAINIER, D.Y. (1999). Gata5 is required for the development of the heart and endoderm in zebrafish. Genes Dev 13: 2983-2995.

ROEBROEK, A.J., UMANS, L., PAULI, I.G., ROBERTSON, E.J., VAN LEUVEN, F., VAN DE VEN, W.J. and CONSTAM, D.B. (1998). Failure of ventral closure and axial rotation in embryos lacking the proprotein convertase Furin. Development 125: 4863-4876.

SAKAMOTO, Y., HARA, K., KANAI-AZUMA, M., MATSUI, T., MIURA, Y., TSUNEKAWA, N., KUROHMARU, M., SAIJOH, Y., KOOPMAN, P. and KANAI, Y. (2007). Redundant roles of Sox17 and Sox18 in early cardiovascular development of mouse embryos. Biochem Biophys Res Commun 360: 539544. 


\section{S. Pfister et al.}

SEGUIN, C.A., DRAPER, J.S., NAGY, A. and ROSSANT, J. (2008). Establishment of endoderm progenitors by SOX transcription factor expression in human embryonic stem cells. Cell Stem Cel/3: 182-195.

SHIVDASANI, R.A. (2002). Molecular regulation of vertebrate early endoderm development. Dev Bio/249: 191-203.

SINNER, D., RANKIN, S., LEE, M. and ZORN, A.M. (2004). Sox17 and beta-catenin cooperate to regulate the transcription of endodermal genes. Development 131: 3069-3080.

SPENCE, J.R., LANGE, A.W., LIN, S.C., KAESTNER, K.H., LOWY, A.M., KIM, I., WHITSETT, J.A. and WELLS, J.M. (2009). Sox17 regulates organ lineage segregation of ventral foregut progenitor cells. Dev Cel/ 17: 62-74.

STAINIER, D.Y. (2002). A glimpse into the molecular entrails of endoderm formation. Genes Dev 16: 893-907.

STURM, K., TAM, P.P. (1993). Isolation and culture of whole postimplantation embryos and germ layer derivatives. Methods Enzymo/225: 164-190.

TAM, P.P., KANAI-AZUMA, M. and KANAI, Y. (2003). Early endoderm development in vertebrates: lineage differentiation and morphogenetic function. Curr Opin Genet Dev 13: 393-400.

TAM, P.P., KHOO, P.L., LEWIS, S.L., BILDSOE, H., WONG, N., TSANG, T.E., GAD, J.M. and ROBB, L. (2007). Sequential allocation and global pattern of movement of the definitive endoderm in the mouse embryo during gastrulation. Development 134: 251-260.
TAM, P.P., TAN, S.S. (1992). The somitogenetic potential of cells in the primitive streak and the tail bud of the organogenesis-stage mouse embryo. Development 115: 703-715.

TREMBLAY, K.D., ZARET, K.S. (2005). Distinct populations of endoderm cells converge to generate the embryonic liver bud and ventral foregut tissues. Dev Bio/280: 87-99.

UEMURA, M., HARA, K., SHITARA, H., ISHII, R., TSUNEKAWA, N., MIURA, Y., KUROHMARU, M., TAYA, C., YONEKAWA, H., KANAI-AZUMA, M. and KANAI, Y. (2010). Expression and function of mouse Sox17 gene in the specification of gallbladder/bile-duct progenitors during early foregut morphogenesis. Biochem.Biophys. Res. Commun. 391: 357-363.

WANG, D., CHANG, P.S., WANG, Z., SUTHERLAND, L., RICHARDSON, J.A., SMALL, E., KRIEG, P.A. and OLSON, E.N. (2001). Activation of cardiac gene expression by myocardin, a transcriptional cofactor for serum response factor. Cel/105: 851-862.

WOODLAND, H.R., ZORN, A.M. (2008). The core endodermal gene network of vertebrates: combining developmental precision with evolutionary flexibility. Bioessays 30: 757-765.

ZORN, A.M., WELLS, J.M. (2007). Molecular basis of vertebrate endoderm development. Int. Rev Cytol. 259: 49-111.

ZORN, A.M., WELLS, J.M. (2009). Vertebrate endoderm development and organ formation. Annu. Rev Cel/ Dev Bio/25: 221-251. 


\section{Further Related Reading, published previously in the Int. J. Dev. Biol.}

See our recent Special Issue Placenta edited by Joan S. Hunt and Kent L. Thornburg at: http://www.ijdb.ehu.es/web/contents.php?vol=54\&issue=2-3

Characterization of mouse embryonic stem cell differentiation into the pancreatic lineage in vitro by transcriptional profiling, quantitative RT-PCR and immunocytochemistry

Alexandra Rolletschek, Insa S. Schroeder, Herbert Schulz, Oliver Hummel, Norbert Huebner and Anna M. Wobus

Int. J. Dev. Biol. (2010) 54: 41-54

Movement and commitment of primitive streak precardiac cells during cardiogenesis

Carmen Lopez-Sanchez, Natividad Garcia-Masa, Carlos M. Gañan and Virginio Garcia-Martinez

Int. J. Dev. Biol. (2009) 53: 1445-1455

Building the vertebrate heart - an evolutionary approach to cardiac development José M. Pérez-Pomares, Juan M. González-Rosa and Ramón Muñoz-Chápuli

Int. J. Dev. Biol. (2009) 53: 1427-1443

Defects of the body plan of mutant embryos lacking Lim1, Otx2 or Hnf3beta activity S J Kinder, T E Tsang, S L Ang, R R Behringer and P P Tam

Int. J. Dev. Biol. (2001) 45: 347-355

Expression of regulatory genes for pancreas development during murine embryonic stem cell differentiation Josué K. Mfopou, Erik Willems, Luc Leyns and Luc Bouwens Int. J. Dev. Biol. (2005) 49: 915-922

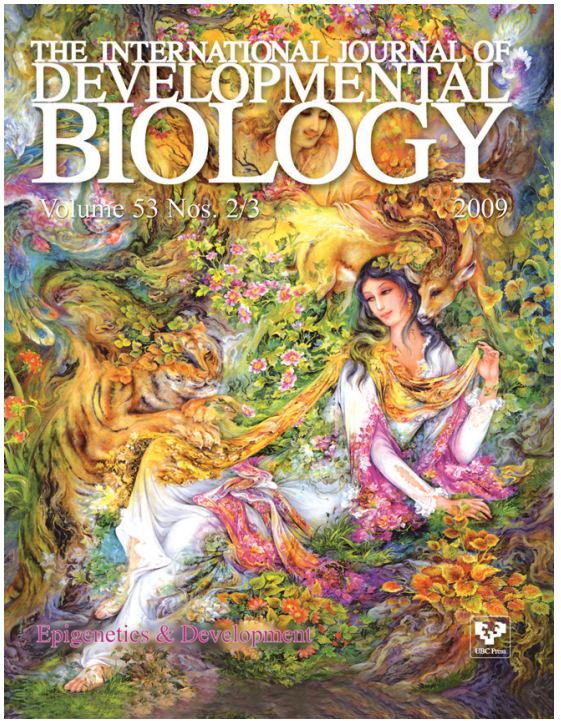

5 yr ISI Impact Factor $(2008)=3.271$

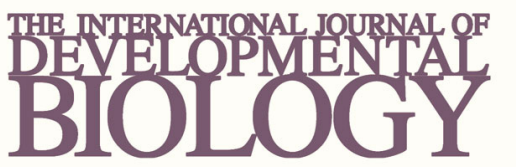

Volume 54 Nos. 6/7
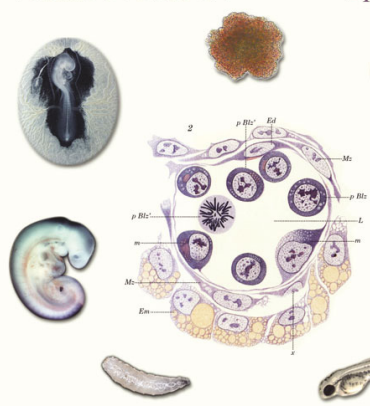

Special Issue

Developmental Hematopoiesis
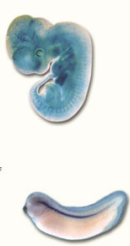

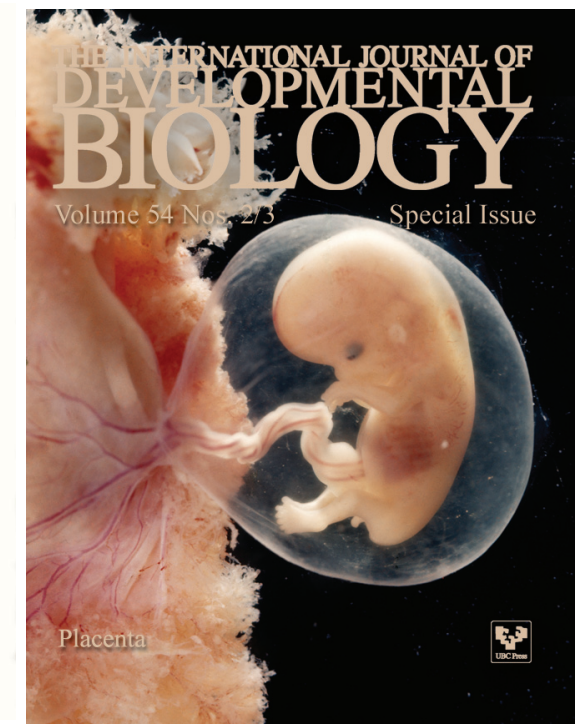

